\title{
DERECHO Y POLÍTICAS AMBIENTALES EN LA UNIÓN EUROPEA
}

(PRIMER SEMESTRE 2017)

\author{
JORGE AGUDO GONZÁLEZ \\ Profesor titular de Derecho Administrativo \\ Universidad Autónoma de Madrid \\ LORENA TRUJILLO PARRA \\ Doctoranda \\ Universidad Autónoma de Madrid
}

\begin{abstract}
Sumario: 1. Introducción. 2. Actividad de las instituciones en el ámbito de la política europea de medio ambiente. 2.1. Actos conjuntos del Consejo y del Parlamento Europeo. 2.1.1. Reglamentos. 2.1.2. Directivas. 2.2. Actos del Consejo. 2.2.1. Reglamentos. 2.2.2. Decisiones. 2.3. Actos del Parlamento. 2.4. Actos de la Comisión. A. Reglamentos. B. Reglamentos de ejecución. C. Reglamentos delegados. D. Decisiones. E. Decisiones de ejecución. F. Directiva de ejecución. G. Dictámenes y comunicaciones. 2.5. Otros. A. Comité de las Regiones. B. Comité Económico y Social.
\end{abstract}

\section{INTRODUCCIÓN}

Esta crónica, como viene siendo habitual, aborda el comentario de los actos jurídicos dictados por las instituciones europeas en esta materia desde el mes de octubre de 2016 hasta mediados de abril del presente año. Durante este período los actos jurídicos dictados han aumentado respecto al número de actos dictados en el último período. En relación con esta materia, gozan de mayor protagonismo, al menos cuantitativamente, los dictados por la Comisión, especialmente los actos de ejecución y modificación de normas aprobadas con anterioridad, aunque en este período se han dictado más actos de los habituales por el Consejo y el Parlamento Europeo. Son escasos, sin embargo, los actos jurídicos no vinculantes dictados por el Comité de las Regiones, aunque no así los dictados por el Comité 
Económico y Social. Desde un punto de vista estrictamente material, tal y como viene siendo habitual, destacan los actos en materia de pesca, sin perjuicio del incremento de los relativos a aditivos para piensos y biocidas.

La exposición se ordenará en función de la institución emisora del acto jurídico, y, dentro de la actividad de cada institución, se atenderá, en la medida de lo posible, a una exposición por materias.

\section{ACTIVIDAD DE LAS INSTITUCIONES EN EL ÁMBITO DE LA POLÍTICA EUROPEA DE MEDIO AMBIENTE}

\subsection{Actos conjuntos del Consejo y del Parlamento Europeo}

\subsubsection{Reglamentos}

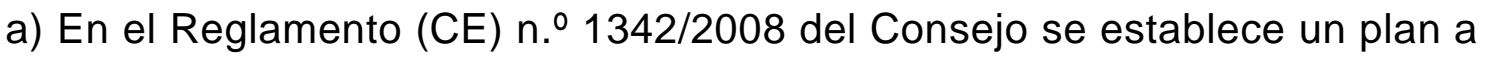
largo plazo para las poblaciones de bacalao del Kattegat, del mar del Norte, del Skagerrak y la Mancha oriental, del oeste de Escocia, y del mar de Irlanda, así como para las pesquerías que las explotan. El objetivo de dicho Reglamento es una explotación sostenible que restablezca y mantenga dichas poblaciones de bacalao por encima de niveles que puedan producir un rendimiento máximo sostenible. La evaluación científica de los resultados del Reglamento (CE) $n .0$ 1342/2008 realizada por el Comité Científico, Técnico y Económico de Pesca ha puesto de manifiesto que la aplicación del Reglamento plantea algunos problemas. El Consejo Internacional para la Exploración del Mar ha propuesto que se reconsidere la estrategia de gestión, en concreto a raíz de su nueva interpretación de la población del mar del Norte. Además, con la aplicación del Reglamento (UE) n. ${ }^{\circ}$ 1380/2013 del Parlamento Europeo y del Consejo, a partir del 1 de enero de 2014 el marco de gestión del bacalao ha cambiado de manera fundamental, en particular mediante la introducción de la obligación de desembarque. Por todo ello, se adopta el Reglamento (UE) 2016/2094 del Parlamento Europeo y del Consejo, de 23 de noviembre de 2016, por el que se modifica el Reglamento (CE) n. 0 1342/2008 del Consejo por el que se establece un plan a largo plazo para las poblaciones de bacalao y las pesquerías que las explotan. 
b) Las actividades pesqueras, en virtud de los principios medioambientales que rigen en la Unión Europea, han de ser sostenibles ambientalmente a largo plazo y gestionarse de forma coherente con los objetivos de generar beneficios económicos, sociales y de empleo, y de contribuir a la disponibilidad de productos alimenticios. La política pesquera común debe aplicar a la gestión de la pesca un enfoque de precaución y ecosistémico a fin de garantizar que las actividades pesqueras tengan un impacto negativo mínimo en el ecosistema marino, así como esforzarse por garantizar que dichas actividades eviten la degradación del medio marino. La Comisión realizó una evaluación del Reglamento (CE) n. 2347/2002 del Consejo y observó, en particular, que se abarcaba una flota excesivamente grande, que no se facilitaba orientación en relación con el control en los puertos designados y con los programas de muestreo, y que la calidad de la información proporcionada por los Estados miembros sobre los niveles de esfuerzo era excesivamente variable. Por otro lado, en la evaluación de la Comisión se llegó a la conclusión de que el límite de capacidad, que se aplica desde 2002, consistente en la capacidad agregada de todos los buques que hayan capturado más de diez toneladas de cualquier mezcla de especies de aguas profundas entre los años 1998 y 2000, no había tenido una repercusión positiva apreciable. En consecuencia, debía actualizarse el régimen de límites de capacidad como parte de las medidas encaminadas a paliar las deficiencias detectadas en dicho Reglamento. Con el fin de adecuar la legislación a dichas evaluaciones, se adopta el Reglamento (UE) 2016/2336 del Parlamento Europeo y del Consejo, de 14 de diciembre de 2016, por el que se establecen condiciones específicas aplicables a la pesca de poblaciones de aguas profundas en el Atlántico Nororiental y disposiciones relativas a la pesca en aguas internacionales del Atlántico Nororiental, y se deroga el Reglamento (CE) n. $² 347 / 2002$ del Consejo.

\subsubsection{Directivas}

En los últimos veinte años se han logrado grandes avances en la Unión en relación con las emisiones atmosféricas antropogénicas y la calidad del 
aire, en particular gracias a una política de la Unión específica, dentro de la que se inscribe la Comunicación de la Comisión, de 21 de septiembre de 2005, titulada "Estrategia temática sobre la contaminación atmosférica". La Directiva 2001/81/CE del Parlamento Europeo y del Consejo ha sido decisiva a este respecto al fijar límites máximos para las emisiones anuales totales de los Estados miembros a partir de 2010 correspondientes al dióxido de azufre $\left(\mathrm{SO}_{2}\right)$, los óxidos de nitrógeno $\left(\mathrm{NO}_{\mathrm{x}}\right)$, los compuestos orgánicos volátiles no metánicos (COVNM) y el amoníaco $\left(\mathrm{NH}_{3}\right)$. A causa de ello, entre 1990 y 2010, las emisiones de dióxido de azufre se redujeron en la Unión en un $82 \%$, las de óxidos de nitrógeno en un $47 \%$, las de compuestos orgánicos volátiles no metánicos en un $56 \%$ y las de amoníaco en un $28 \%$.

No obstante, como se indica en la Comunicación de la Comisión, de 18 de diciembre de 2013, titulada "Aire Puro para Europa" (en lo sucesivo, ETCA), sigue habiendo importantes efectos negativos y riesgos para la salud humana y el medio ambiente.

El Séptimo Programa de Medio Ambiente confirma el objetivo a largo plazo de la Unión sobre calidad del aire de alcanzar unos niveles de calidad del aire tales que no haya importantes efectos negativos y riesgos para la salud humana $o$ el medio ambiente, $y$, a tal fin, insta a que se cumplan plenamente la legislación de la Unión vigente sobre calidad del aire y los objetivos y acciones estratégicos para después de 2020. Asimismo, insta a que se redoblen esfuerzos en las zonas en las que la población y los ecosistemas están expuestos a niveles elevados de contaminantes atmosféricos y a que se refuercen las sinergias entre la legislación sobre calidad del aire y los objetivos estratégicos que se ha marcado la Unión, en particular en materia de cambio climático y biodiversidad.

La ETCA establece nuevos objetivos estratégicos para el período que concluye en 2030 con el fin de avanzar hacia el objetivo de la Unión a largo plazo sobre calidad del aire. Atendiendo, por tanto, a esos nuevos objetivos, el régimen de techos nacionales de emisión establecido por la Directiva 2001/81/CE debe revisarse para adaptarlo a los compromisos internacionales de la Unión y los Estados miembros. A tal efecto, se adopta 
la Directiva (UE) 2016/2284 del Parlamento Europeo y del Consejo, de 14 de diciembre de 2016, relativa a la reducción de las emisiones nacionales de determinados contaminantes atmosféricos, por la que se modifica la Directiva 2003/35/CE y se deroga la Directiva 2001/81/CE.

Los objetivos de la Directiva son: 1) contribuir a alcanzar, de modo eficiente en términos de costes, los objetivos de calidad del aire establecidos en la legislación de la Unión y a mitigar los efectos del cambio climático, además de a mejorar la calidad del aire a nivel mundial y las sinergias con las políticas de la Unión en materia de clima y energía, a la vez que se evitan duplicidades en la legislación de la Unión vigente; 2) contribuir a reducir los costes que la contaminación atmosférica en la Unión ocasiona en el ámbito de la salud, al mejorar el bienestar de los ciudadanos de la Unión, así como a favorecer la transición a una economía verde; y 3) contribuir a la reducción progresiva de la contaminación atmosférica al añadirse a las reducciones logradas mediante la legislación de la Unión dirigida a controlar la contaminación atmosférica en la fuente por emisiones de determinadas sustancias.

Los compromisos nacionales de reducción de emisiones para cualquier año del período 2020 a 2029 son idénticos a los del Protocolo de Gotemburgo revisado. A tal efecto, cada Estado miembro debe elaborar, adoptar y aplicar un programa nacional de control de la contaminación atmosférica con el fin de cumplir sus compromisos de reducción de emisiones y contribuir efectivamente a la consecución de los objetivos de calidad del aire.

\subsection{Actos del Consejo}

\subsubsection{Reglamentos}

a) El artículo 43, apartado 3, del Tratado de Funcionamiento de la Unión Europea dispone que corresponda al Consejo, a propuesta de la Comisión, adoptar medidas relativas a la fijación y reparto de posibilidades de pesca, incluidas, si procede, determinadas condiciones relacionadas funcionalmente con ellas. 
Las posibilidades de pesca han de asignarse a los Estados miembros de tal modo que se garantice la estabilidad relativa de las actividades pesqueras de cada uno de ellos en relación con cada población o pesquería y teniendo debidamente en cuenta los objetivos de la política pesquera común establecidos en el Reglamento (UE) $n .{ }^{\circ}$ 1380/2013. Este Reglamento exige que las medidas de conservación se adopten teniendo en cuenta los dictámenes científicos, técnicos y económicos disponibles, incluidos, cuando proceda, los informes elaborados por el Comité Científico, Técnico y Económico de Pesca y otros organismos consultivos, así como el asesoramiento facilitado por los consejos consultivos y las recomendaciones conjuntas de los Estados miembros.

A tales efectos, el Reglamento (UE) 2016/1139 del Parlamento Europeo y del Consejo estableció un plan plurianual para las poblaciones de bacalao, arenque y espadín del mar Báltico para las pesquerías que explotan estas poblaciones. El objetivo del plan es garantizar que la explotación de los recursos biológicos marinos vivos restablezca y mantenga las poblaciones de especies capturadas por encima de niveles que puedan producir el rendimiento máximo sostenible. A tal fin, es conveniente establecer los límites de capturas aplicables en 2017 para las poblaciones de bacalao, arenque y espadín del mar Báltico con el objetivo de lograr los objetivos del plan.

Según el plan, si los dictámenes científicos indican que la biomasa reproductora de cualquiera de las poblaciones afectadas se sitúa por debajo de los puntos de referencia de la biomasa de población reproductora establecidos en el anexo II del Reglamento (UE) 2016/1139, es preciso adoptar todas las medidas correctoras apropiadas para garantizar un rápido retorno de las poblaciones de peces afectadas a niveles superiores a los niveles que puedan dar lugar al rendimiento máximo sostenible.

El Consejo Internacional para la Exploración del Mar ha indicado que la biomasa de bacalao del Báltico occidental está por debajo de los puntos de referencia de conservación establecidos en el anexo II de dicho Reglamento. Por consiguiente, es conveniente que las posibilidades de pesca se fijen por debajo y adoptar medidas correctoras adicionales. Una 
prórroga de dos semanas del actual período de veda de seis semanas aumentaría la protección de la población reproductora de bacalao. Según los dictámenes científicos, la pesca recreativa del bacalao del Báltico occidental contribuye significativamente a la mortalidad global por pesca de esta población. Habida cuenta del estado actual de esta población, conviene adoptar determinadas medidas relativas a la pesca recreativa. Más concretamente, conviene aplicar un límite de capturas por pescador y día más restrictivo durante el período de desove. Ello sin perjuicio del principio de estabilidad relativa aplicable a las actividades de pesca comercial. Ocurre lo mismo en lo que respecta al arenque en el golfo de Riga.

Por todo ello, se debe adoptar el Reglamento (UE) 2016/1903 del Consejo, de 28 de octubre de 2016, por el que se establecen, para 2017, las posibilidades de pesca para determinadas poblaciones y grupos de poblaciones de peces aplicables en el mar Báltico y por el que se modifica el Reglamento (UE) 2016/72.

b) El último dictamen científico del Consejo Internacional para la Exploración del Mar y del Comité Científico, Técnico y Económico de Pesca indica que la mayor parte de las poblaciones de peces de aguas profundas se captura de forma insostenible y que, para garantizar su sostenibilidad, las posibilidades de pesca deben seguir reduciéndose hasta que la evolución del tamaño de las poblaciones muestre una tendencia positiva. Con el fin de adecuar la regulación vigente a estos nuevos informes, se adopta el Reglamento (UE) 2016/2285 del Consejo, de 12 de diciembre de 2016, por el que se fijan para los buques pesqueros de la Unión las posibilidades de pesca en 2017 y 2018 de determinadas poblaciones de peces de aguas profundas y se modifica el Reglamento (UE) 2016/72 del Consejo.

c) En esta materia se dicta también el Reglamento (UE) 2016/2372 del Consejo, de 19 de diciembre de 2016, por el que se establecen, para 2017, las posibilidades de pesca aplicables a determinadas poblaciones y grupos de poblaciones de peces en el mar Negro. El presente Reglamento fija las posibilidades de pesca para 2017 de determinadas poblaciones de peces 
en el mar Negro por los buques pesqueros de la Unión que enarbolan pabellón de Bulgaria y Rumanía en relación con las especies de rodaballo (Psetta maxima) y de espadín (Sprattus sprattus).

d) En este contexto, se dicta igualmente el Reglamento (UE) 2017/127 del Consejo, de 20 de enero de 2017, por el que se establecen, para 2017, las posibilidades de pesca para determinadas poblaciones y grupos de poblaciones de peces, aplicables en aguas de la Unión y, en el caso de los buques pesqueros de la Unión, en determinadas aguas no pertenecientes a la Unión. Asimismo, se aprueba el Reglamento (UE) 2017/135 del Consejo, de 23 de enero de 2017, que modifica el Reglamento (UE) 2016/1903, por el que se establecen, para 2017, las posibilidades de pesca para determinadas poblaciones y grupos de poblaciones de peces aplicables en el mar Báltico.

\subsubsection{Decisiones}

a) Decisión (UE) 2017/3 del Consejo, de 19 de diciembre de 2016, relativa a la celebración del Acuerdo entre la Unión Europea y el Reino de Noruega sobre el acceso recíproco a la pesca en el Skagerrak para los buques que enarbolan pabellón de Dinamarca, Noruega o Suecia. El 16 de febrero de 2015, el Reino de Noruega notificó a la Unión Europea la conclusión de sus procedimientos necesarios para la entrada en vigor del Acuerdo entre la Unión Europea y el Reino de Noruega sobre el acceso recíproco a la pesca en el Skagerrak para los buques que enarbolan pabellón de Dinamarca, Noruega o Suecia.

De igual modo, el 19 de diciembre de 2016, la Unión Europea notificó al Reino de Noruega que el Consejo había concluido, en nombre de la Unión Europea, los procedimientos necesarios para la entrada en vigor del Acuerdo, firmado en Bruselas el 15 de enero de 2015. Por consiguiente, el Acuerdo entró en vigor el 19 de diciembre de 2016, de conformidad con lo dispuesto en su artículo 7.

b) Decisión (UE) 2017/436 del Consejo, de 6 de marzo de 2017, relativa a la firma, en nombre de la Unión Europea, del Acuerdo entre la Unión Europea y la República de Chile sobre el comercio de productos 
orgánicos/ecológicos. En el Acuerdo adoptado entre la Unión y la República de Chile ambas partes reconocen la equivalencia de sus respectivas normas de producción orgánica/ecológica y de los sistemas de control de los productos orgánicos/ecológicos. El Acuerdo tiene como objetivo fomentar el comercio de productos orgánicos/ecológicos, contribuir al desarrollo y la expansión del sector orgánico/ecológico en la Unión y en la República de Chile y alcanzar un alto nivel de respeto de los principios de la producción orgánica/ecológica, de garantía de los sistemas de control y de integridad de los productos orgánicos/ecológicos. Asimismo, pretende mejorar la protección de los respectivos logotipos ecológicos/orgánicos de la Unión y de la República de Chile y aumentar la cooperación normativa entre las partes sobre cuestiones relativas a la producción orgánica/ecológica.

\subsection{Actos del Parlamento}

a) El Parlamento Europeo, tras un detenido estudio de la Decisión del Consejo (10883/2014) y de las posiciones de los Estados miembros y de la Comisión de Medio Ambiente, Salud Pública y Seguridad Alimentaria (A80166/2015), concede su aprobación al proyecto de Decisión del Consejo relativa a la celebración, en nombre de la Unión Europea, del Acuerdo entre la Unión Europea y sus Estados miembros, por una parte, e Islandia, por otra, sobre la participación de Islandia en el cumplimiento conjunto de los compromisos de la Unión Europea, sus Estados miembros e Islandia en el segundo período de compromiso del Protocolo de Kioto de la Convención Marco de las Naciones Unidas sobre el Cambio Climático, mediante la Resolución legislativa, de 10 de junio de 2015 (10883/2014 - C80088/2015 - 2014/0151(NLE)), (2016/C 407/18).

b) En este sentido, igualmente, el Parlamento Europeo, vistas la enmienda al Protocolo de Kioto adoptada en el octavo período de sesiones de la Conferencia de las Partes reunidas en calidad de Partes en el Protocolo de Kioto, celebrada en Doha, Qatar, en diciembre de 2012, y la solicitud de aprobación presentada por el Consejo de conformidad con el artículo 192, apartado 1, así como con el artículo 218, apartado 6, párrafo segundo, letra 
a), del Tratado de Funcionamiento de la Unión Europea (C8- 0029/2015), concede su aprobación a la celebración sobre el proyecto de Decisión del Consejo relativa a la celebración, en nombre de la Unión Europea, de la enmienda de Doha al Protocolo de Kioto de la Convención Marco de las Naciones Unidas sobre el Cambio Climático y al cumplimiento conjunto de los compromisos contraídos con arreglo a este, a través de la Resolución legislativa del Parlamento Europeo, de 10 de junio de 2015 (10400/2014 C8-0029/2015 - 2013/0376(NLE)).

c) Los delitos contra las especies silvestres -en particular, la caza furtiva y el aprovechamiento ilegal, el tráfico de productos ilegales de la fauna y flora silvestres y sus derivados, la venta y la utilización ilegales de estos productos en países consumidores - suponen una grave actividad delictiva organizada transnacional con un volumen de al menos 19.000 millones de dólares estadounidenses al año. Es la cuarta mayor actividad ilegal del mundo, tras el tráfico de drogas, la falsificación y la trata de seres humanos. Asimismo, el tráfico ilícito de especies silvestres suele implicar redes transnacionales de delincuencia organizada y sirve de fuente de ingresos para dichas redes y para grupos armados rebeldes. Además, los delitos contra las especies silvestres constituyen una amenaza al bienestar de los animales y a la conservación de las especies de animales y plantas afectadas, y pone en peligro los ecosistemas locales en su conjunto. Por todo ello, acoge favorablemente la Resolución de abril de 2013, de la Comisión de las Naciones Unidas de Prevención del Delito y Justicia Penal, respaldada por el Consejo Económico y Social de las Naciones Unidas en julio de 2013, en la que se animaba a los Estados miembros de las Naciones Unidas a considerar el tráfico ilícito de flora y fauna silvestres como un delito grave en el caso de que lo cometan grupos delictivos organizados, equiparándolo con la trata de seres humanos y el tráfico de drogas. Se adopta la Resolución del Parlamento Europeo, de 15 de enero de 2014, sobre los delitos contra las especies silvestres (2013/2747(RSP)), (2016/C 482/12).

En esta dirección, el Parlamento insta a la Comisión a que establezca sin demora un plan de acción de la UE para luchar contra los delitos contra las 
especies silvestres y contra el tráfico de especies silvestres dotado de objetivos concretos y plazos claros. Hace hincapié en que la UE es un destino importante del tráfico ilegal de productos derivados de especies silvestres, como el marfil o animales vivos, y que, por tanto, se encuentra en una posición privilegiada para controlar este comercio. Por otro lado, insta a que se apliquen todas las normas que regulan esta materia, tales como el Reglamento (CE) núm. 338/97, a fin de disuadir a los autores de delitos contra las especies silvestres, o la Directiva 2008/99/CE, relativa a la protección del medio ambiente mediante el Derecho penal, entre otras.

En segundo lugar, pide a los Estados miembros que impongan moratorias a todas las importaciones y exportaciones comerciales, ventas nacionales y adquisiciones de colmillos y productos de marfil bruto o elaborado hasta que las poblaciones de elefantes silvestres dejen de estar amenazadas por la caza furtiva. Les pide, igualmente, que, mediante la destrucción de sus reservas de marfil ilegal, se unan a otros firmantes de la Convención sobre el Comercio Internacional de Especies Amenazadas de Fauna y Flora Silvestres para enviar un mensaje claro en contra del tráfico de especies silvestres y de la demanda de productos ilegales derivados de especies silvestres.

Anima a los Estados miembros a que refuercen el sistema judicial en la UE aumentando la concienciación, las capacidades y los recursos a fin de garantizar que los procesos penales contra el tráfico de especies silvestres se desarrollen con eficacia y con todo el alcance de la ley, así como que se impongan a los responsables de delitos contra las especies silvestres penas acordes con la gravedad del delito; insta, por ello, a la Comisión a que racionalice la armonización entre los Estados miembros en el marco de la Recomendación núm. 2007/425/CE de la Comisión a fin de evitar que los Estados miembros con penas inferiores sean preferidos como punto de entrada.

d) Se dicta la Resolución del Parlamento Europeo, de 14 de enero de 2014, sobre una estrategia europea frente a los residuos de plásticos en el medio ambiente (2013/2113(INI)), (2016/C 482/09). La legislación de la Unión no contempla específicamente los residuos de plásticos, sino que se tratan 
como una parte de los flujos generales de residuos, sin que se valoren sus características particulares. Este tipo de residuos no debe entenderse como un mero desecho, sino como un recurso. La Resolución considera que los materiales plásticos son cada vez más diversos y que su uso está aumentando, lo que conlleva un incremento del volumen de residuos y de sus combinaciones con otros materiales y compuestos. De hecho, el plástico se acumula en grandes cantidades (se estima que un total de ochenta millones de toneladas se encuentran flotando en los océanos Atlántico y Pacífico) y permanece en el medio ambiente durante siglos, destruyendo la vida marina, provocando reacciones tóxicas y liberando alteradores endocrinos —sustancias que son cancerígenas, mutagénicas o tóxicas para la reproducción-, nanopartículas y contaminantes orgánicos persistentes en los ecosistemas y, por tanto, en la cadena alimentaria. Solo en 2010 se pusieron en el mercado 95.500 millones de bolsas de plástico, la mayoría de ellas destinadas a un único uso, a pesar de estar restringidas o prohibidas en muchos países. Por todo ello, se considera que hay que incidir en la prevención y la minimización, fomentando que los productores opten por materiales alternativos y más sostenibles cuando diseñan sus productos, así como en la ecoinnovación, que es crucial para la competitividad europea, ya que ayuda a que la industria se adapte a las presiones generadas por los elevados precios de los recursos y la escasez de materiales, y crea tecnologías facilitadoras esenciales para una sociedad sostenible.

Asimismo, acoge con satisfacción el Libro Verde de la Comisión y reconoce la necesidad de incorporar medidas específicas sobre los residuos de plásticos en la legislación de la UE, así como de impulsar una aplicación y ejecución más uniformes, consistentes y rigurosas de la legislación vigente en materia de residuos, especialmente con respecto a la jerarquía de residuos (prevención, reutilización, reciclaje y recuperación), y, en particular, en aquellos Estados miembros que todavía no hayan alcanzado los objetivos y fines existentes.

\subsection{Actos de la Comisión}




\section{A. Reglamentos}

a) El Reglamento (CE) n. $\cong$ 338/97 enumera en diversas listas las especies de animales y plantas cuyo comercio está limitado o controlado. Dichas listas incorporan las que figuran en los apéndices de la Convención sobre el Comercio Internacional de Especies Amenazadas de Fauna y Flora Silvestres. Asimismo, incorporan otras especies cuyo estado de conservación exige regular o supervisar su comercio dentro de la Unión o con origen o destino en la Unión.

En la 17a Reunión de la Conferencia de las Partes en la Convención, celebrada en Johannesburgo (Sudáfrica) del 24 de septiembre al 4 de octubre de 2016 (CoP 17), se introdujeron algunas enmiendas en los apéndices de la Convención. Esas enmiendas deben incorporarse a los anexos del Reglamento (CE) n.. 338/97.

Las especies siguientes han sido incluidas recientemente en el apéndice III de la Convención: Dalbergia calycina, Dalbergia cubilquitzensis, Dalbergia glomerata y Dalbergia tucurensis (todas con anotación), a petición de Guatemala; Cedrela fissilis y Cedrela lilloi (ambas con anotación), a petición de Brasil; y Pterocarpus erinaceus (con anotación), a petición de Senegal. La especie Cairina moschata se ha retirado del apéndice III de la Convención a petición de Honduras. A tales efectos, se debe adecuar esta inclusión, dando lugar a la adopción del Reglamento (UE) 2016/2029 de la Comisión, de 10 de noviembre de 2016, por el que se modifica el Reglamento (CE) n. 338/97 del Consejo, relativo a la protección de especies de la fauna y flora silvestres mediante el control de su comercio.

b) En este marco, se adoptan igualmente para la inclusión o modificación de otro sinfín de especies el Reglamento (UE) 2017/160 de la Comisión, de 20 de enero de 2017, por el que se modifica el Reglamento (CE) n. 0 338/97 del Consejo, relativo a la protección de especies de la fauna y flora silvestres mediante el control de su comercio, y el Reglamento (UE) 2017/128 de la Comisión, de 20 de enero de 2017, por el que se modifica el Reglamento (CE) n.. 338/97 del Consejo, relativo a la protección de especies de la fauna y flora silvestres mediante el control de su comercio. 
c) Reglamento (UE) 2017/605 de la Comisión, de 29 de marzo de 2017, por el que se modifica el anexo VI del Reglamento (CE) n. $1005 / 2009$ del Parlamento Europeo y del Consejo, sobre las sustancias que agotan la capa de ozono.

El anexo VI del Reglamento (CE) n. ${ }^{0}$ 1005/2009 fija unas fechas límite a partir de las cuales no deben utilizarse halones para los extintores o los sistemas de protección contra incendios en los "nuevos aparatos", incluso en las aeronaves nuevas. De conformidad con el anexo VI, punto 2, letra b), del Reglamento (CE) n.․ 1005/2009, la definición de "nuevos aparatos" depende de la fecha de presentación de una solicitud de certificación de tipo a la oportuna autoridad reguladora.

En aras de la claridad jurídica y de la coherencia en la aplicación del Reglamento (CE) n.ำ 1005/2009, es necesario especificar en la definición de "nuevos aparatos", recogida en el anexo $\mathrm{VI}$, punto 2, letra b), del Reglamento (CE) n. $.1005 / 2009$, que, en lo que respecta a las aeronaves, la solicitud de certificación de tipo solo se refiere a una solicitud de nueva certificación de tipo y no cubre las modificaciones introducidas en una certificación de tipo existente. Esto estaría asimismo en consonancia con el concepto utilizado en las normas relativas a los halones por la Organización de Aviación Civil Internacional. Procede, por tanto, modificar el Reglamento (CE) n. $.1005 / 2009$ y, en consecuencia, se dicta el Reglamento (UE) 2017/605 de la Comisión, de 29 de marzo de 2017, por el que se modifica el anexo VI del Reglamento (CE) n. $1005 / 2009$ del Parlamento Europeo y del Consejo, sobre las sustancias que agotan la capa de ozono.

d) En materia de residuos de plaguicidas, la Comisión ha consultado con los laboratorios de referencia de la Unión Europea sobre la necesidad de adaptar diversos límites de determinación analítica. Estos laboratorios concluyeron que el progreso técnico permite, para ciertas mercancías, establecer límites más bajos de determinación analítica de diversas sustancias.

En los anexos del Reglamento (CE) n. 396/2005 se fijaron los límites máximos de estos residuos (LMR). En el marco de un procedimiento de 
autorización del uso de determinados productos fitosanitarios, se presentaron varias solicitudes de modificación de estos límites. De

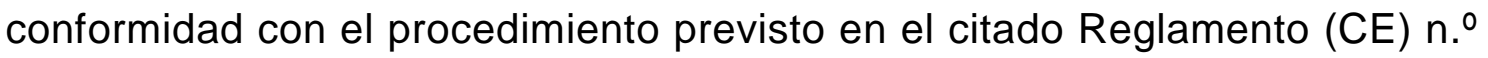
396/2005, los Estados miembros afectados evaluaron estas solicitudes y enviaron los correspondientes informes de evaluación a la Comisión. La Autoridad Europea de Seguridad Alimentaria estudió las solicitudes y los informes de evaluación, prestando especial atención a los riesgos para el consumidor y, en su caso, para los animales. Finalmente, emitió dictámenes motivados sobre los LMR propuestos y remitió dichos dictámenes a la Comisión y a los Estados miembros y los puso a disposición del público.

De acuerdo con los dictámenes motivados de la Autoridad Europea de Seguridad Alimentaria y de la Organización Mundial del Comercio, una vez consultados los socios comerciales de la Unión y teniendo en cuenta los factores pertinentes para la cuestión objeto de consideración, las modificaciones pertinentes de los LMR cumplen los requisitos del Reglamento (CE) n. 396/2005. En consecuencia, se admiten las solicitudes presentadas y para ello se adoptan los siguientes reglamentos:

- Reglamento (UE) 2016/1822 de la Comisión, de 13 de octubre de 2016, que modifica los anexos II, III y V del Reglamento (CE) n.ํ 396/2005 del Parlamento Europeo y del Consejo en lo relativo a los límites máximos de residuos de aclonifeno, deltametrina, fluazinam, metomilo, sulcotriona y tiodicarb en determinados productos.

- Reglamento (UE) 2016/1866 de la Comisión, de 17 de octubre de 2016, por el que se modifican los anexos II, III y V del Reglamento (CE) n. ${ }^{\circ}$ 396/2005 del Parlamento Europeo y del Consejo en lo relativo a los límites máximos de residuos de 3-decen-2-ona, acibenzolar-S-metilo y hexaclorobenceno en determinados productos.

- Reglamento (UE) 2016/1902 de la Comisión, de 27 de octubre de 2016, que modifica los anexos II y III del Reglamento (CE) n.ํ 396/2005 del Parlamento Europeo y del Consejo en lo relativo a los límites máximos de residuos de acetamiprid, ametoctradina, azoxistrobina, ciflutrina, ácido difluoroacético, dimetomorfo, fenpirazamina, flonicamid, fluazinam, 
fludioxonil, flupiradifurona, flutriafol, fluxapiroxad, metconazol, proquinazid, protioconazol, piriproxifeno, espirodiclofeno y trifloxistrobina en determinados productos.

- Reglamento (UE) 2017/170 de la Comisión, de 30 de enero de 2017, por el que se modifican los anexos II, III y V del Reglamento (CE) n. $.396 / 2005$ del Parlamento Europeo y del Consejo por lo que respecta a los límites máximos de residuos de bifentrina, carbetamida, cinidón-etilo, fenpropimorfo y triflusulfurón en o sobre determinados productos.

- Reglamento (UE) 2017/171 de la Comisión, de 30 de enero de 2017, por el que se modifican los anexos II, III y IV del Reglamento (CE) n. ${ }^{\circ}$ 396/2005 del Parlamento Europeo y del Consejo por lo que respecta a los límites máximos de residuos de aminopiralida, azoxistrobina, ciantraniliprol, ciflufenamida, ciproconazol, dietofencarb, ditiocarbamatos, fluazifop-P, fluopiram, haloxifop, isofetamida, metalaxilo, pirimetanil, prohexadiona, propaquizafop, Trichoderma atroviride (cepa SC1) y zoxamida en o sobre determinados productos.

- Reglamento (UE) 2017/405 de la Comisión, de 8 de marzo de 2017, que modifica los anexos II y III del Reglamento (CE) n. 0 396/2005 del Parlamento Europeo y del Consejo por lo que respecta a los límites máximos de residuos del sulfoxaflor en determinados productos.

- Reglamento (UE) 2017/623 de la Comisión, de 30 de marzo de 2017, que modifica los anexos II y III del Reglamento (CE) $n . .396 / 2005$ del Parlamento Europeo y del Consejo por lo que respecta a los límites máximos de residuos del acequinocilo, el amitraz, el cumafós, el diflufenicán, la flumequina, la metribuzina, la permetrina, la piraclostrobina y la estreptomicina en determinados productos.

- Reglamento (UE) 2017/624 de la Comisión, de 30 de marzo de 2017,

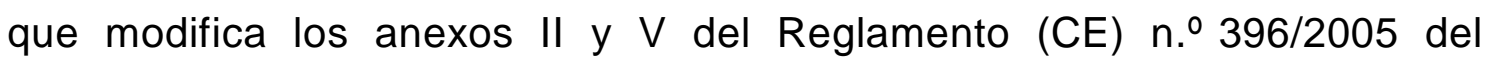
Parlamento Europeo y del Consejo por lo que respecta a los límites máximos de residuos del bifenazato, la daminozida y la tolilfluanida en determinados productos. 
- Reglamento (UE) 2017/405 de la Comisión, de 8 de marzo de 2017, que modifica los anexos II y III del Reglamento (CE) n. $0396 / 2005$ del Parlamento Europeo y del Consejo por lo que respecta a los límites máximos de residuos del sulfoxaflor en determinados productos.

- Reglamento (UE) 2017/623 de la Comisión, de 30 de marzo de 2017, que modifica los anexos II y III del Reglamento (CE) n. 0 396/2005 del Parlamento Europeo y del Consejo por lo que respecta a los límites máximos de residuos del acequinocilo, el amitraz, el cumafós, el diflufenicán, la flumequina, la metribuzina, la permetrina, la piraclostrobina y la estreptomicina en determinados productos.

- Reglamento (UE) 2017/624 de la Comisión, de 30 de marzo de 2017, que modifica los anexos II y V del Reglamento (CE) n. 396/2005 del Parlamento Europeo y del Consejo por lo que respecta a los límites máximos de residuos del bifenazato, la daminozida y la tolilfluanida en determinados productos.

e) Finalmente, en este mismo ámbito, se han dictado el Reglamento de Ejecución (UE) 2017/12 de la Comisión, de 6 de enero de 2017, relativo a la forma y al contenido de las solicitudes y las peticiones para la fijación de los límites máximos de residuos de conformidad con el Reglamento (CE) n. 9 470/2009 del Parlamento Europeo y del Consejo, y el Reglamento de Ejecución (UE) 2017/201 de la Comisión, de 6 de febrero de 2017, por el que se modifica el Reglamento (UE) n. 37/2010 para clasificar la sustancia fluralaner en lo que respecta a su límite máximo de residuos.

f) Para terminar, en relación con las disposiciones pesqueras que prohíben la pesca de determinadas especies en aguas internacionales y de la Unión Europea, se han dictado los siguientes reglamentos:

- Reglamento (UE) 2016/1911 de la Comisión, de 28 de octubre de 2016, por el que se prohíbe la pesca de sable negro en aguas de la Unión e internacionales de las zonas VIII, IX y X por parte de los buques que enarbolan pabellón de España. 
- Reglamento (UE) 2016/1912 de la Comisión, de 28 de octubre de 2016, por el que se prohíbe la pesca de alfonsinos en aguas de la Unión e internacionales de las zonas III, IV, V, VI, VII, VIII, IX, X, XII y XIV por parte de los buques que enarbolan pabellón de España.

- Reglamento (UE) 2016/2138 de la Comisión, de 2 de diciembre de 2016, por el que se prohíbe a los buques que enarbolan pabellón de Portugal la pesca de raya mosaico en aguas de la Unión de la zona IX.

- Reglamento (UE) 2016/2139 de la Comisión, de 2 de diciembre de 2016, por el que se prohíbe a los buques que enarbolan pabellón de Bélgica la pesca de rayas, incluidas la raya santiguesa, la raya común, la raya boca de rosa, la raya pintada, la raya cimbreira y la raya mosaico, en aguas de la Unión de la zona VIld y las condiciones especiales aplicables en aguas de la Unión de las zonas Vla, VIb, VIla a VIlc y VIle a VIlk.

- Reglamento (UE) 2016/2140 de la Comisión, de 2 de diciembre de 2016, por el que se prohíbe a los buques que enarbolan pabellón de España la pesca de atún blanco del norte en el océano Atlántico, al norte del paralelo $5^{\circ} \mathrm{N}$.

- Reglamento (UE) 2016/2211 de la Comisión, de 6 de diciembre de 2016, por el que se prohíbe la pesca de besugo en aguas de la Unión y aguas internacionales de las subzonas VI, VII y VIII por parte de los buques que enarbolan pabellón de Francia.

- Reglamento (UE) 2016/2343 de la Comisión, de 14 de diciembre de 2016, por el que se prohíbe a los buques que enarbolan pabellón de España la pesca de raya mosaico en aguas de la Unión de la zona VIII.

- Reglamento (UE) 2016/2344 de la Comisión, de 14 de diciembre de 2016, por el que se prohíbe la pesca de solla en las zonas VIIh, VIlj y VIlk por parte de los buques que enarbolan pabellón de Francia.

- Reglamento (UE) 2016/2361 de la Comisión, de 15 de diciembre de 2016, por el que se prohíbe la pesca de brótola de fango en aguas de la Unión y aguas internacionales de las zonas VIII y IX y en aguas de la Unión 
y aguas internacionales de las zonas V, VI y VII por parte de los buques que enarbolan pabellón de Portugal.

- Reglamento (UE) 2017/452 de la Comisión, de 13 de marzo de 2017, por el que se prohíbe temporalmente la pesca de rape en las zonas VIIlc, IX y $\mathrm{X}$ y en las aguas de la Unión del CPACO 34.1.1 por parte de los buques que enarbolan pabellón de Francia.

- Reglamento (UE) 2017/453 de la Comisión, de 13 de marzo de 2017, por el que se prohíbe temporalmente a los buques que enarbolan pabellón de Bélgica la pesca de raya mosaico en aguas de la Unión de la división VIId.

- Reglamento (UE) 2017/641 de la Comisión, de 3 de abril de 2017, por el que se prohíbe temporalmente la pesca de besugo en aguas de la Unión y aguas internacionales de las subzonas VI, VII y VIII por parte de los buques que enarbolan pabellón de Francia.

- Reglamento (UE) 2017/642 de la Comisión, de 3 de abril de 2017, por el que se prohíbe temporalmente la pesca de aguja azul en el océano Atlántico por parte de los buques que enarbolan pabellón de España.

- Reglamento (UE) 2017/643 de la Comisión, de 3 de abril de 2017, por el que se prohíbe temporalmente la pesca de aguja blanca en el océano Atlántico por parte de los buques que enarbolan pabellón de España.

- Reglamento (UE) 2017/452 de la Comisión, de 13 de marzo de 2017, por el que se prohíbe temporalmente la pesca de rape en las zonas VIIlc, IX y $\mathrm{X}$ y en las aguas de la Unión del CPACO 34.1.1 por parte de los buques que enarbolan pabellón de Francia.

- Reglamento (UE) 2017/453 de la Comisión, de 13 de marzo de 2017, por el que se prohíbe temporalmente a los buques que enarbolan pabellón de Bélgica la pesca de raya mosaico en aguas de la Unión de la división VIId.

- Reglamento (UE) 2017/641 de la Comisión, de 3 de abril de 2017, por el que se prohíbe temporalmente la pesca de besugo en aguas de la Unión 
y aguas internacionales de las subzonas VI, VII y VIII por parte de los buques que enarbolan pabellón de Francia.

- Reglamento (UE) 2017/642 de la Comisión, de 3 de abril de 2017, por

el que se prohíbe temporalmente la pesca de aguja azul en el océano Atlántico por parte de los buques que enarbolan pabellón de España.

- Reglamento (UE) 2017/643 de la Comisión, de 3 de abril de 2017, por el que se prohíbe temporalmente la pesca de aguja blanca en el océano Atlántico por parte de los buques que enarbolan pabellón de España.

\section{B. Reglamentos de ejecución}

a) En el capítulo $V$ del Reglamento (CE) n.ำ 1005/2008 se establecen los procedimientos para la identificación de los buques pesqueros que practican una pesca ilegal, no declarada y no reglamentada (en lo sucesivo, INDNR) y para la adopción de una lista de la Unión de tales buques. En el artículo 30.1 se establece que deben inscribirse en la lista de la Unión los buques inscritos en listas de buques de pesca INDNR adoptadas por organizaciones regionales de ordenación pesquera. Así, todas las organizaciones regionales de ordenación pesquera elaboran y actualizan periódicamente listas de buques de pesca INDNR de acuerdo con sus respectivas normas. De conformidad con dicho artículo, tras recibir de las organizaciones regionales de ordenación pesquera las listas de buques presunta o notoriamente involucrados en la pesca ilegal, no declarada y no reglamentada, la Comisión debe actualizar la lista de la Unión. Dado que la Comisión ha recibido nuevas listas de las organizaciones regionales de ordenación pesquera, debe actualizarse la lista de la Unión, que fue

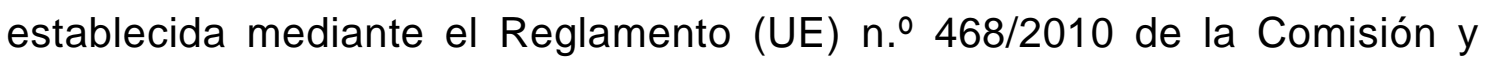
modificada posteriormente por otros reglamentos de ejecución. Por ello, se procede a dictar el Reglamento de Ejecución (UE) 2016/1852 de la Comisión, de 19 de octubre de 2016, que modifica el Reglamento (UE) $\mathrm{n}$.. 468/2010, por el que se establece la lista de la UE de los buques que practican una pesca ilegal, no declarada y no reglamentada.

b) En relación con los reglamentos de ejecución dictados por la Comisión, podemos destacar especialmente las autorizaciones relativas al uso de 
diferentes sustancias como aditivo en piensos para todas las especies animales y, en menor medida, para su uso en biocidas. El Reglamento (CE) n. - 1831/2003 regula el uso de aditivos en la alimentación animal y establece los motivos y procedimientos para su autorización. En este ámbito, se han presentado numerosas solicitudes de autorización de diferentes productos como aditivo en piensos. Así, la Autoridad Europea de Seguridad Alimentaria, competente en la materia, concluyó que, en las condiciones de uso propuestas, estos productos no tienen efectos adversos para la salud animal, la salud humana ni el medio ambiente, y que pueden considerarse eficaces en lo que se refiere a su contribución para cumplir los requisitos de contenido en la alimentación de las especies animales. Por consiguiente, procede autorizar el uso de dichas sustancias según lo especificado en sus anexos mediante los siguientes actos:

- Reglamento de Ejecución (UE) 2016/1833 de la Comisión, de 17 de octubre de 2016, relativo a la autorización de un preparado de lectinas de judías (lectinas de Phaseolus vulgaris) como aditivo en piensos para lechones (titular de la autorización, Biolek, Sp. z o.o.).

- Reglamento de Ejecución (UE) 2016/1881 de la Comisión, de 24 de octubre de 2016, que modifica el Reglamento de Ejecución (UE) n. $9837 / 2012$ en lo que respecta a la actividad mínima de 6 -fitasa producida por Aspergillus oryzae (DSM 22594) como aditivo en los piensos para cerdas (titular de la autorización: DSM Nutritional Products Ltd).

- Reglamento de Ejecución (UE) 2016/2150 de la Comisión, de 7 de diciembre de 2016, relativo a la autorización de los preparados de Lactobacillus plantarum DSM 29025 y Lactobacillus plantarum NCIMB 42150 como aditivos en los piensos para todas las especies animales.

- Reglamento de Ejecución (UE) 2016/2261 de la Comisión, de 15 de diciembre de 2016, relativo a la autorización del óxido de cobre (I) como aditivo en piensos para todas las especies de animales.

- Reglamento de Ejecución (UE) 2017/53 de la Comisión, de 14 de diciembre de 2016, relativo a la autorización del butan-1-ol, el hexan-1-ol, el octan-1-ol, el nonan-1-ol, el dodecan-1-ol, el heptan-1-ol, el decan-1-ol, el 
pentan-1-ol, el etanol, el acetaldehído, el propanal, el butanal, el pentanal, el hexanal, el octanal, el decanal, el dodecanal, el nonanal, el heptanal, el undecanal, el 1,1-dietoxietano, el ácido fórmico, el ácido acético, el ácido propiónico, el ácido valérico, el ácido hexanoico, el ácido octanoico, el ácido decanoico, el ácido dodecanoico, el ácido oleico, el ácido hexadecanoico, el ácido tetradecanoico, el ácido heptanoico, el ácido nonanoico, el acetato de etilo, el acetato de propilo, el acetato de butilo, el acetato de hexilo, el acetato de octilo, el acetato de nonilo, el acetato de decilo, el acetato de dodecilo, el acetato de heptilo, el acetato de metilo, el butirato de metilo, el butirato de butilo, el butirato de pentilo, el butirato de hexilo, el butirato de octilo, el decanoato de etilo, el hexanoato de etilo, el hexanoato de propilo, el hexanoato de pentilo, el hexanoato de hexilo, el hexanoato de metilo, el formiato de etilo, el dodecanoato de etilo, el tetradecanoato de etilo, el nonanoato de etilo, el octanoato de etilo, el propionato de etilo, el propionato de metilo, el valerato de etilo, el valerato de butilo, el hex-3enoato de etilo, el hexadecanoato de etilo, el trans-2-butenoato de etilo, el undecanoato de etilo, el isovalerato de butilo, el isobutirato de hexilo, el 2metilbutirato de metilo, el 2-metilbutirato de hexilo, el citrato de trietilo, el isovalerato de hexilo y el 2-metilvalerato de metilo como aditivos para piensos destinados a todas las especies animales.

- Reglamento de Ejecución (UE) 2017/54 de la Comisión, de 14 de diciembre de 2016, relativo a la autorización del 2-metilpropan-1-ol, el isopentanol, el 3,7-dimetiloctan-1-ol, el 2-etilhexan-1-ol, el 2-metilpropanal, el 3-metilbutanal, el 2-metilbutiraldehído, el ácido 3-metilbutírico, el ácido 2metilvalérico, el ácido 2-etilbutírico, el ácido 2-metilbutírico, el ácido 2metilheptanoico, el ácido 4-metilnonanoico, el ácido 4-metiloctanoico, el acetato de isobutilo, el butirato de isobutilo, el hexanoato de 3-metilbutilo, el dodecanoato de 3-metilbutilo, el octanoato de 3-metilbutilo, el propionato de 3-metilbutilo, el formiato de 3-metilbutilo, el tributirato de glicerilo, el isobutirato de isobutilo, el isobutirato de isopentilo, el isovalerato de isobutilo, el 2-metilbutirato de isopentilo, el isovalerato de 2-metilbutilo y el butirato de 2-metilbutilo como aditivos para piensos destinados a todas las especies animales. 
- Reglamento de Ejecución (UE) 2017/55 de la Comisión, de 14 de diciembre de 2016, relativo a la autorización de octan-2-ol, isopropanol, pentan-2-ol, octan-3-ol, heptan-2-ona, pentan-2-ona, 6-metil-hepta-3,5-dien2-ona, nonan-3-ona, decan-2-ona y tetradecanoato de isopropilo como aditivos en los piensos para todas las especies animales.

- Reglamento de Ejecución (UE) 2017/56 de la Comisión, de 14 de diciembre de 2016, relativo a la autorización de ácido láctico, ácido 4oxovalérico, ácido succínico, ácido fumárico, acetoacetato de etilo, lactato de etilo, lactato de butilo, 4-oxovalerato de etilo, succinato de dietilo, malonato de dietilo, O-butirilactato de butilo, lactato de hex-3-enilo, lactato de hexilo, butiro-1,4-lactona, decano-1,5-lactona, undecano-1,5-lactona, pentano-1,4-lactona, nonano-1,5-lactona, octano-1,5-lactona, heptano-1,4lactona y hexano-1,4-lactona como aditivos en los piensos para todas las especies animales.

- Reglamento de Ejecución (UE) 2017/57 de la Comisión, de 14 de diciembre de 2016, relativo a la autorización del 1,8-cineol, la 3,4dihidrocumarina y el 2-(2-metilprop-1-enil)-4-metiltetrahidropirano como aditivos en los piensos para todas las especies animales.

- Reglamento de Ejecución (UE) 2017/59 de la Comisión, de 14 de diciembre de 2016, relativo a la autorización de 1,1-dimetoxi-2-feniletano, formiato de fenetilo, octanoato de fenetilo, isobutirato de fenetilo, 2metilbutirato de fenetilo y benzoato de fenetilo como aditivos en los piensos para todas las especies animales.

- Reglamento de Ejecución (UE) 2017/61 de la Comisión, de 14 de diciembre de 2016, relativo a la autorización del 4-alil-2,6-dimetoxifenol y del acetato de eugenilo como aditivos en los piensos para todas las especies animales, salvo los peces y las aves de corral.

- Reglamento de Ejecución (UE) 2017/62 de la Comisión, de 14 de diciembre de 2016, relativo a la autorización de 3-(metiltio)propionaldehído, 3-(metiltio)propionato de metilo, aliltiol, sulfuro de dimetilo, sulfuro de dibutilo, disulfuro de dialilo, trisulfuro de dialilo, trisulfuro de dimetilo, disulfuro de dipropilo, isotiocianato de alilo, disulfuro de dimetilo, 2- 
metilbenceno-1-tiol, butanotioato de S-metilo, disulfuro de alilo y metilo, 3(metiltio)propan-1-ol, 3-(metiltio)hexan-1-ol, 1-propano-1-tiol, sulfuro de dialilo, 2,4-ditiapentano, 2-metil-2-(metilditio)propanal, 2-metilpropano-1-tiol, metilsulfinilmetano, propano-2-tiol, 3,5-dimetil-1,2,4-tritiolano y 2-metil-4propil-1,3-oxatiano como aditivos en los piensos para todas las especies animales.

- Reglamento de Ejecución (UE) 2017/63 de la Comisión, de 14 de diciembre de 2016, relativo a la autorización de alcohol bencílico, alcohol 4isopropilbencílico, benzaldehído, 4-isopropilbenzaldehído, salicilaldehído, ptolualdehído, 2-metoxibenzaldehído, ácido benzoico, acetato de bencilo, butirato de bencilo, formiato de bencilo, propionato de bencilo, hexanoato de bencilo, isobutirato de bencilo, isovalerato de bencilo, salicilato de hexilo, fenilacetato de bencilo, benzoato de metilo, benzoato de etilo, benzoato de isopentilo, salicilato de pentilo y benzoato de isobutilo como aditivos en los piensos para todas las especies animales y de veratraldehído y ácido gálico como aditivos en los piensos para determinadas especies animales.

- Reglamento de Ejecución (UE) 2017/64 de la Comisión, de 14 de diciembre de 2016, relativo a la autorización del ácido glicirrícico amoniacal como aditivo en los piensos destinados a todas las especies animales.

- Reglamento de Ejecución (UE) 2017/64 de la Comisión, de 14 de diciembre de 2016, relativo a la autorización del ácido glicirrícico amoniacal como aditivo en los piensos destinados a todas las especies animales.

- Reglamento de Ejecución (UE) 2017/66 de la Comisión, de 14 de diciembre de 2016, relativo a la autorización del ácido tánico como aditivo en piensos para todas las especies animales.

- Reglamento de Ejecución (UE) 2017/194 de la Comisión, de 3 de febrero de 2017, relativo a la autorización del preparado de Lactobacillus diolivorans DSM 32074 como aditivo en piensos para todas las especies animales. 
- Reglamento de Ejecución (UE) 2017/210 de la Comisión, de 7 de febrero de 2017, relativo a la autorización de un preparado de endo-1,4beta-xilanasa y endo-1,3(4)-beta-glucanasa, producidas por Talaromyces versatilis sp. nov. IMI CC 378536 y Talaromyces versatilis sp. nov. DSM 26702, como aditivo alimentario para gallinas ponedoras (titular de la autorización: Adisseo France S.A.S.).

- Reglamento de ejecución (UE) 2017/211 de la Comisión, de 7 de febrero de 2017, relativo a la autorización del preparado de endo-1,4-betaxilanasa (EC 3.2.1.8) producida por Bacillus subtilis (LMG-S 15136) como aditivo en piensos para aves de corral, lechones destetados y cerdos de engorde, y por el que se modifican los Reglamentos (CE) n. ${ }^{0}$ 1259/2004, (CE) n. $.1206 / 2005$ y (CE) n. 322/2009 y se deroga el Reglamento (CE) n.. 516/2007 (titular de la autorización: Beldem, una división de Puratos $N V)$.

- Reglamento de Ejecución (UE) 2017/307 de la Comisión, de 21 de febrero de 2017, relativo a la autorización del extracto seco de uva Vitis vinifera spp. vinifera como aditivo en los piensos para todas las especies animales, excepto los perros.

- Reglamento de Ejecución (UE) 2017/420 de la Comisión, de 9 de marzo de 2017, relativo a la autorización de un preparado de aceite de tomillo, aceite sintético de anís estrellado y polvo de corteza de quilaya como aditivo en piensos para pollos de engorde, pollitas para puesta y especies menores de aves para engorde o para puesta (titular de la autorización: Delacon Biotechnik $\mathrm{GmbH}$ ).

- Reglamento de Ejecución (UE) 2017/429 de la Comisión, de 10 de marzo de 2017, relativo a la autorización de un preparado de endo-1,3(4)beta-glucanasa producida por Aspergillus aculeatinus (anteriormente clasificado como Aspergillus aculeatus) (CBS 589.94), endo-1,4-betaglucanasa producida por Trichoderma reesei (anteriormente clasificado como Trichoderma longibrachiatum) (CBS 592.94), alfa-amilasa producida por Bacillus amyloliquefaciens (DSM 9553) y endo-1,4-beta-xilanasa producida por Trichoderma viride (NIBH FERM BP4842) como aditivo en 
piensos para todas las especies aviares, y por el que se modifican los Reglamentos (CE) $n . .358 / 2005$ y (CE) $n . .1284 / 2006$ y se deroga el Reglamento (UE) n.ำ516/2010 (titular de la autorización Kemin Europa NV).

- Reglamento de Ejecución (UE) 2017/440 de la Comisión, de 13 de marzo de 2017, relativo a la autorización del preparado de Bacillus amyloliquefaciens (PTA-6507), Bacillus amyloliquefaciens (NRRL B-50013) y Bacillus amyloliquefaciens (NRRL B-50104) como aditivo en piensos para pollos de engorde, pollitas criadas para puesta, especies menores de aves de corral para engorde y especies menores de aves de corral criadas para puesta [titular de la autorización: Danisco (UK) Ltd, que actúa bajo el nombre de Danisco Animal Nutrition].

- Reglamento de Ejecución (UE) 2017/447 de la Comisión, de 14 de marzo de 2017, relativo a la autorización del preparado de Bacillus subtilis (DSM 5750) y Bacillus licheniformis (DSM 5749) como aditivo en piensos para cerdas, lechones destetados, cerdos de engorde, terneros de cría y pavos de engorde, y por el que se modifican los Reglamentos (CE) n.o 1453/2004, (CE) n. 2148/2004 y (CE) n. 600/2005 (titular de la autorización: Chr. Hansen $A / S)$.

- Reglamento de Ejecución (UE) 2017/455 de la Comisión, de 15 de marzo de 2017, relativo a la autorización de un preparado de Lactobacillus fermentum (NCIMB 41636), Lactobacillus plantarum (NCIMB 41638) y Lactobacillus rhamnosus (NCIMB 41640) como aditivo en los piensos para perros.

- Reglamento de Ejecución (UE) 2017/420 de la Comisión, de 9 de marzo de 2017, relativo a la autorización de un preparado de aceite de tomillo, aceite sintético de anís estrellado y polvo de corteza de quilaya como aditivo en piensos para pollos de engorde, pollitas para puesta y especies menores de aves para engorde o para puesta (titular de la autorización: Delacon Biotechnik $\mathrm{GmbH}$ ).

- Reglamento de Ejecución (UE) 2017/429 de la Comisión, de 10 de marzo de 2017, relativo a la autorización de un preparado de endo-1,3(4)beta-glucanasa producida por Aspergillus aculeatinus (anteriormente 
clasificado como Aspergillus aculeatus) (CBS 589.94), endo-1,4-betaglucanasa producida por Trichoderma reesei (anteriormente clasificado como Trichoderma longibrachiatum) (CBS 592.94), alfa-amilasa producida por Bacillus amyloliquefaciens (DSM 9553) y endo-1,4-beta-xilanasa producida por_Trichoderma viride (NIBH FERM BP4842) como aditivo en piensos para todas las especies aviares, y por el que se modifican los Reglamentos (CE) n.. 358/2005 y (CE) n. $.01284 / 2006$ y se deroga el Reglamento (UE) n.ำ516/2010 (titular de la autorización Kemin Europa NV).

- Reglamento de Ejecución (UE) 2017/439 de la Comisión, de 13 de marzo de 2017, relativo a la autorización del sulfato de L-lisina producido por_Escherichia coli como aditivo para piensos destinados a todas las especies animales.

- Reglamento de Ejecución (UE) 2017/440 de la Comisión, de 13 de marzo de 2017, relativo a la autorización del preparado de Bacillus amyloliquefaciens (PTA-6507), Bacillus amyloliquefaciens (NRRL B-50013) y_Bacillus amyloliquefaciens (NRRL B-50104) como aditivo en piensos para pollos de engorde, pollitas criadas para puesta, especies menores de aves de corral para engorde y especies menores de aves de corral criadas para puesta [titular de la autorización: Danisco (UK) Ltd, que actúa bajo el nombre de Danisco Animal Nutrition].

- Reglamento de Ejecución (UE) 2017/447 de la Comisión, de 14 de marzo de 2017, relativo a la autorización del preparado de Bacillus subtilis (DSM 5750) y Bacillus licheniformis (DSM 5749) como aditivo en piensos para cerdas, lechones destetados, cerdos de engorde, terneros de cría y pavos de engorde, y por el que se modifican los Reglamentos (CE) n.. 1453/2004, (CE) n.. 2148/2004 y (CE) n.. 600/2005 (titular de la autorización:

Chr. Hansen

$A / S)$.

- Reglamento de Ejecución (UE) 2017/455 de la Comisión, de 15 de marzo de 2017, relativo a la autorización de un preparado de Lactobacillus fermentum (NCIMB 41636), Lactobacillus plantarum (NCIMB 41638) y Lactobacillus rhamnosus (NCIMB 41640) como aditivo en los piensos para perros. 
c) Por otro lado, la Comisión ha dictado los siguientes actos en relación con la aprobación de determinadas sustancias activas contenidas en biocidas:

- Reglamento de Ejecución (UE) 2016/1929 de la Comisión, de 4 de noviembre de 2016, por el que se aprueba el uso de la sustancia activa Bacillus thuringiensis, subsp. kurstaki, serotipo 3a3b, cepa ABTS-351, para su uso en los biocidas del tipo de producto 18.

- Reglamento de Ejecución (UE) 2016/1930 de la Comisión, de 4 de noviembre de 2016, por el que se aprueba el clorocresol como sustancia activa existente para su uso en biocidas de los tipos de producto 1, 2, 3, 6 y 9.

- Reglamento de Ejecución (UE) 2016/1931 de la Comisión, de 4 de noviembre de 2016, por el que se aprueba el uso del clorocresol como sustancia activa existente en biocidas del tipo de producto 13.

- Reglamento de Ejecución (UE) 2016/1932 de la Comisión, de 4 de noviembre de 2016, por el que se aprueba el uso del óxido de calcio y magnesio (cal viva dolomítica) como sustancia activa existente en biocidas de los tipos de producto 2 y 3 .

- Reglamento de Ejecución (UE) 2016/1933 de la Comisión, de 4 de noviembre de 2016, por el que se aprueba el uso del tetrahidróxido de calcio y magnesio (cal dolomítica hidratada) como sustancia activa existente en biocidas de los tipos de producto 2 y 3 .

- Reglamento de Ejecución (UE) 2016/1934 de la Comisión, de 4 de noviembre de 2016, por el que se aprueba el uso del cloruro de alquiltrimetilamonio de coco (ATMAC/TMAC) como sustancia activa existente en biocidas del tipo de producto 8 .

- Reglamento de Ejecución (UE) 2016/1935 de la Comisión, de 4 de noviembre de 2016, por el que se aprueba el uso del dihidróxido de calcio (cal hidratada) como sustancia activa existente en biocidas de los tipos de producto 2 y 3 . 
- Reglamento de Ejecución (UE) 2016/1936 de la Comisión, de 4 de noviembre de 2016, por el que se aprueba el uso del óxido de calcio (cal viva) como sustancia activa existente en biocidas de los tipos de producto 2 y 3.

- Reglamento de Ejecución (UE) 2016/1937 de la Comisión, de 4 de noviembre de 2016, por el que se aprueba el uso de la ciflutrina como sustancia activa existente en biocidas del tipo de producto 18.

- Reglamento de Ejecución (UE) 2016/1938 de la Comisión, de 4 de noviembre de 2016, por el que se aprueba el uso del ácido cítrico como sustancia activa existente en biocidas del tipo de producto 2 .

- Reglamento de Ejecución (UE) 2016/2288 de la Comisión, de 16 de diciembre de 2016, por el que se aprueba el uso del butóxido de piperonilo como sustancia activa existente en biocidas del tipo de producto 18.

- Reglamento de Ejecución (UE) 2016/2289 de la Comisión, de 16 de diciembre de 2016, por el que se aprueba la epsilon-Momfluorotrina como sustancia activa en biocidas del tipo de producto 18.

- Reglamento de Ejecución (UE) 2016/2290 de la Comisión, de 16 de diciembre de 2016, por el que se aprueba el uso del ácido peracético como sustancia activa existente en biocidas de los tipos de producto 11 y 12 .

- Reglamento de Ejecución (UE) 2016/2291 de la Comisión, de 16 de diciembre de 2016, por el que se aprueba el ácido láctico $L(+)$ como sustancia activa para su uso en biocidas del tipo de producto 1.

- Reglamento de Ejecución (UE) 2017/438 de la Comisión, de 13 de marzo de 2017, por el que se modifica el Reglamento de Ejecución (UE) n.․ $540 / 2011$ en lo relativo a las condiciones de aprobación de la sustancia activa abamectina.

- Reglamento de Ejecución (UE) 2017/555 de la Comisión, de 24 de marzo de 2017, que modifica el Reglamento de Ejecución (UE) n.ํ 540/2011 por lo que respecta a la prórroga de los períodos de aprobación de varias sustancias activas incluidas en la parte B del anexo del Reglamento de Ejecución (UE) n.ำ686/2012 (programa de renovación AIR IV). 
d) En otro orden de cosas, la Unión Europea concede gran importancia a la protección de la salud humana y animal y del medio ambiente. La estandarización de las normas que regulan la venta de productos fitosanitarios ayuda a lograr este objetivo, garantiza el buen funcionamiento del mercado único y mejora la producción agrícola. En este sentido, el Reglamento (CE) n. $.1107 / 2009$ del Parlamento Europeo y del Consejo, de 21 de octubre de 2009, relativo a la comercialización de productos fitosanitarios y por el que se derogan las Directivas 79/117/CEE y 91/414/CEE del Consejo, establece normas para autorizar la venta, el uso y el control de los productos fitosanitarios en la Unión Europea (UE). Asimismo, reconoce el principio de cautela que los países de la UE pueden aplicar cuando exista incertidumbre científica acerca de los riesgos que un producto fitosanitario pueda plantear para la salud humana o animal o para el medio ambiente. Además, el Reglamento de Ejecución (UE) n. $540 / 2011$ de la Comisión, de 25 de mayo de 2011, por el que se aplica el Reglamento (CE) n. $-1107 / 2009$ del Parlamento Europeo y del Consejo en lo que respecta a la lista de sustancias activas autorizadas, que ha sido modificado y completado en varias ocasiones, regula una lista de las sustancias activas que se considera que han sido autorizadas en el marco del Reglamento (CE) n. $.1107 / 2009$ y de las sustancias activas autorizadas con arreglo a dicha regulación en partes separadas del anexo. En este contexto, se han dictado numerosos actos que autorizan y complementan las sustancias activas autorizadas.

- Reglamento de Ejecución (UE) 2016/2016 de la Comisión, de 17 de noviembre de 2016, por el que se modifica el Reglamento (UE) n. ${ }^{\circ}$ 540/2011 en lo que se refiere a la prórroga de los períodos de aprobación de las sustancias activas acetamiprid, ácido benzoico, flazasulfurón, mecoprop-p, mepanipirima, mesosulfurón, piraclostrobina, propiconazol, propineb, propizamida, propoxicarbazona, Pseudomonas chlororaphis, cepa MA 342, quinoxifeno, tiacloprid, tiram, ziram y zoxamida.

- Reglamento de Ejecución (UE) 2016/2035 de la Comisión, de 21 de noviembre de 2016, por el que se modifica el Reglamento de Ejecución 


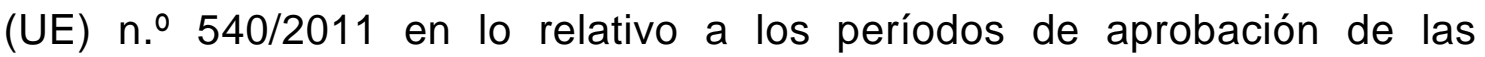
sustancias activas fipronil y maneb.

- Reglamento de Ejecución (UE) 2017/357 de la Comisión, de 28 de febrero de 2017, por el que se establece la no aprobación de la sustancia activa ciclaniliprol, de conformidad con el Reglamento (CE) n.ำ 1107/2009 del Parlamento Europeo y del Consejo, relativo a la comercialización de productos fitosanitarios.

- Reglamento de Ejecución (UE) 2017/358 de la Comisión, de 28 de febrero de 2017, por el que se confirman las condiciones de aprobación de la sustancia activa acrinatrina que figuran en el Reglamento de Ejecución (UE) $n . .540 / 201$.

- Reglamento de Ejecución (UE) 2017/359 de la Comisión, de 28 de febrero de 2017, por el que se modifica el Reglamento de Ejecución (UE) n. ${ }^{\circ}$ 540/2011 en lo relativo a las condiciones de aprobación de la sustancia activa oxifluorfeno.

- Reglamento de Ejecución (UE) 2017/360 de la Comisión, de 28 de febrero de 2017, por el que se modifica el Reglamento de Ejecución (UE) n. $.540 / 2011$ en lo relativo a las condiciones de aprobación de la sustancia activa buprofezina.

e) El artículo 6, apartados 1 y 3, del Reglamento (UE) 2015/757 obliga a las empresas a presentar al verificador un plan de seguimiento consistente en una descripción exhaustiva y transparente del método de seguimiento aplicado a cada buque incluido en el ámbito de aplicación de dicho Reglamento.

Para garantizar que dichos planes de seguimiento contengan información normalizada que permita una aplicación armonizada de las obligaciones de seguimiento y notificación, es preciso establecer modelos, incluidas normas técnicas para su aplicación uniforme, tal y como se ha venido realizando. Sin embargo, con el fin de agilizar y mejorar este procedimiento, se dicta el Reglamento de Ejecución (UE) 2016/1927 de la Comisión, de 4 de 
noviembre de 2016, sobre los modelos de los planes de seguimiento, los informes de emisiones y los documentos de conformidad contemplados en el Reglamento (UE) 2015/757 del Parlamento Europeo y del Consejo relativo al seguimiento, notificación y verificación de las emisiones de dióxido de carbono generadas por el transporte marítimo, en el cual se incluye un modelo electrónico para los informes de emisiones. Esto es necesario para que los informes de emisiones verificadas se presenten por vía electrónica y contengan información agregada anual completa y normalizada que pueda hacerse pública y permita a la Comisión elaborar los informes exigidos en virtud del artículo 21 del Reglamento (UE) $2015 / 757$.

En este sentido, se dicta igualmente el Reglamento de Ejecución (UE) 2016/1928 de la Comisión, de 4 de noviembre de 2016, sobre la determinación de la carga transportada por categorías de buques que no sean buques de pasaje, buques de transbordo rodado o buques portacontenedores, de conformidad con el Reglamento (UE) 2015/757 del Parlamento Europeo y del Consejo, relativo al seguimiento, notificación y verificación de las emisiones de dióxido de carbono generadas por el transporte marítimo.

\section{Reglamentos delegados}

a) Con el fin de garantizar la coherencia y la eficacia del sistema de homologación de tipo Unión Europea de los vehículos de la categoría L, es necesario mejorar continuamente los requisitos técnicos y los procedimientos de ensayo establecidos en esos actos delegados y adaptarlos al progreso técnico. También es necesario mejorar la claridad de esos actos delegados. En este sentido, en materia medioambiental una de las medidas contra las emisiones excesivas de hidrocarburos procedentes de los vehículos de la categoría L consiste en mantener las emisiones de evaporación dentro de los límites de masa de hidrocarburos establecidos en el anexo VI, parte C, del Reglamento (UE) n. 168/2013. Para ello, en el momento de la homologación de tipo debe realizarse un ensayo de tipo IV para medir las emisiones de evaporación del vehículo. Uno de los requisitos 
del ensayo de tipo IV por el método SHED (cámara hermética para determinar las emisiones de evaporación) es la instalación de un filtro de carbón activo sometido a envejecimiento rápido, o bien, si se instala un filtro de carbón activo desverdizado, la aplicación de un factor de deterioro suplementario. En el estudio de los efectos medioambientales al que se

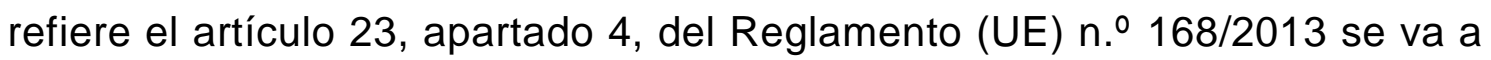
investigar si es o no rentable mantener este factor de deterioro como alternativa a la instalación de un filtro de carbón activo sometido a envejecimiento rápido y que sea representativo. Si el resultado del estudio demuestra que este método no es rentable, se presentará a su debido tiempo una propuesta de supresión de esta alternativa, cuya fecha de aplicación ha de ser posterior a la fase Euro 5. Asimismo, se debe adaptar la durabilidad de los dispositivos de control de la contaminación al progreso técnico. Por todo ello, procede modificar los reglamentos delegados dictados en esta materia y, en consecuencia, se dicta el Reglamento Delegado (UE) 2016/1824 de la Comisión, de 14 de julio de 2016, que modifica el Reglamento Delegado (UE) $n .{ }^{\circ} 3 / 2014$, el Reglamento Delegado

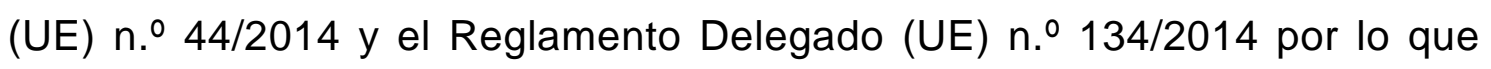
respecta, respectivamente, a los requisitos de seguridad funcional de los vehículos, a los requisitos de fabricación de los vehículos y los requisitos generales y a los requisitos de eficacia medioambiental y rendimiento de la unidad de propulsión.

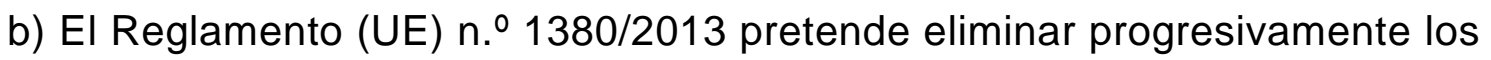
descartes en todas las pesquerías de la Unión introduciendo la obligación de desembarcar las capturas de las especies sujetas a límites de capturas. En su artículo 15, apartado 6, se faculta a la Comisión para adoptar planes de descartes por medio de un acto delegado durante un período no superior a tres años, sobre la base de recomendaciones conjuntas establecidas por los Estados miembros en consulta con los consejos consultivos pertinentes. En este sentido, se dicta el Reglamento Delegado (UE) 2016/2250 de la Comisión, de 4 de octubre de 2016, por el que se establece un plan de descartes para determinadas pesquerías demersales en el mar del Norte y en aguas de la Unión de la división CIEM Ila, mediante el cual se incluyen 
una exención por alta capacidad de supervivencia de las capturas de cigala en la subzona CIEM IV para determinados artes, con la condición de que se utilice un dispositivo de selectividad Netgrid, y una exención por alta capacidad de supervivencia de las capturas de lenguado común en la subzona CIEM IV para determinados artes y con determinadas condiciones que favorecen la supervivencia de esta especie. Asimismo, se incluye una exención de minimis para las capturas combinadas de lenguado común, eglefino y merlán con determinadas redes de arrastre de fondo en la división CIEM IIla; una exención de minimis para las capturas combinadas de lenguado, eglefino y merlán con nasas en la división CIEM IIla; y, para 2018, una exención de minimis para el merlán capturado con redes de arrastre de fondo en la división CIEM IVc. Finalmente, se faculta a la Comisión para establecer, a efectos de la aprobación de los planes de descartes y para las especies sujetas a la obligación de desembarque, tallas mínimas de referencia a efectos de conservación con el fin de garantizar la protección de los juveniles de organismos marinos.

En este sentido, se adopta igualmente el Reglamento Delegado (UE) 2016/2374 de la Comisión, de 12 de octubre de 2016, por el que se establece un plan de descartes para determinadas pesquerías demersales en aguas suroccidentales, cuyo plan de descartes para 2017 debe abarcar las pesquerías de lenguado común, merluza, rape y cigala (solamente en el interior de las zonas de distribución de las poblaciones a que se hace referencia como "unidades funcionales") en las divisiones VIIla, VIIIb, VIIId y VIIle del CIEM; las de cigala en las divisiones VIIIc y IXa del CIEM (solo en el interior de unidades funcionales); las del lenguado común y la solla en la división IXa del CIEM; la de la merluza en las divisiones VIIlc y IXa del CIEM; y la del rape en las divisiones VIIIa, VIIIb, VIIIc, VIIId, VIIle y IXa del CIEM. Incluye tres exenciones de minimis respecto de la obligación de desembarque para determinadas pesquerías y dentro de determinados límites: 1) la aplicable al lenguado común, hasta un máximo del 5\% del total anual de capturas de esta especie por parte de los buques que la pescan en las divisiones VIIla y VIIIb del CIEM con redes de arrastre de vara y redes de arrastre de fondo, se basa en la enorme dificultad de alcanzar una 
mayor selectividad; 2) la correspondiente al lenguado común, hasta un máximo del 3\% del total anual de capturas de esta especie por parte de los buques que la pescan en las divisiones VIIla y VIIIb del CIEM con trasmallos y redes de enmalle, se basa en el hecho de que la viabilidad de incrementar la selectividad resulta muy difícil de conseguir; y 3) para la merluza, hasta un máximo del 7\% en 2017 y del 6\% en 2018 del total anual de capturas de esta especie por parte de los buques que la pescan en las divisiones VIII y IX del CIEM con redes de arrastre, se basa en la enorme dificultad de alcanzar una mayor selectividad.

Asimismo, se dicta el Reglamento Delegado (UE) 2016/2375 de la Comisión, de 12 de octubre de 2016, por el que se establece un plan de descartes para determinadas pesquerías demersales en aguas noroccidentales, el cual determinó las flotas que estarían sujetas a la obligación de desembarque en las pesquerías mixtas de bacalao, eglefino, merlán y carbonero, en las pesquerías de cigala, en la pesquería mixta de lenguado común y solla, y en las pesquerías de la merluza y el abadejo.

También, se dicta el Reglamento Delegado (UE) 2016/2376 de la Comisión, de 13 de octubre de 2016, por el que se establece un plan de descartes para moluscos bivalvos Venus spp. en las aguas territoriales italianas, pues, según las conclusiones del Comité Científico, Técnico y Económico de la Pesca sobre el plan nacional de gestión de los descartes de Venus spp., esta especie es una de las que tiene una alta tasa de supervivencia, lo cual justifica una solicitud de excepción a la obligación de desembarque para la fracción de las capturas descartada. Una reducción de $25 \mathrm{~mm}$ a $22 \mathrm{~mm}$ de una talla mínima de referencia a efectos de conservación no es incompatible con la longitud en la madurez, por lo que no debe tener un impacto significativo en la protección de los juveniles. Se prevé que solo dará lugar a una pequeña reducción del potencial de reproducción de las poblaciones, lo cual no parece que tenga mucho impacto sobre la población. Por último, se llegó a la conclusión de que la propuesta de programa de seguimiento científico puede proporcionar datos suficientes para evaluar los efectos del plan de descartes. 
También se dicta el Reglamento Delegado (UE) 2016/2377 de la Comisión, de 14 de octubre de 2016, que modifica el Reglamento Delegado (UE) n.음 1394/2014, por el que se establece un plan de descartes para determinadas pesquerías pelágicas en las aguas suroccidentales, mediante el cual se fija en $12 \mathrm{~cm}$ la talla mínima de referencia a efectos de conservación para el jurel (Trachurus spp.) en la división VIIlc y la subzona IX del CIEM en lo que respecta a un $5 \%$ de las cuotas respectivas de España y Portugal. Además, establece que, dentro de este límite del $5 \%$ de la cuota de jurel, en la pesca artesanal en playas con redes de cerco (xávega) en la división IXa del CIEM, el $1 \%$ de la cuota de Portugal pudiera ser capturada con una talla inferior a $12 \mathrm{~cm}$.

Se adopta también el Reglamento Delegado (UE) 2017/86 de la Comisión, de 20 de octubre de 2016, por el que se establece un plan de descartes para determinadas pesquerías demersales en el mar Mediterráneo, con el fin de aplicar una exención a la obligación de desembarque al lenguado común (Solea solea) en el mar Adriático y a los moluscos bivalvos vieiras (Pecten jacobeus), almejas (Venerupis spp.) y chirlas (Venus spp.) en el mar Mediterráneo occidental, ya que pueden producirse altas tasas de supervivencia, teniendo en cuenta las características de las artes y las prácticas de pesca y del ecosistema.

Para finalizar, en este contexto se adopta igualmente el Reglamento Delegado (UE) 2017/87 de la Comisión, de 20 de octubre de 2016, por el que se establece un plan de descartes para la pesca del rodaballo en el mar Negro, para aplicar una exención de la obligación de desembarque a la pesca del rodaballo en el mar Negro, ya que las pruebas científicas indican altas tasas de supervivencia.

\section{Decisiones}

El Acuerdo de colaboración en el sector pesquero entre la Comunidad Europea y el Reino de Marruecos, aprobado mediante el Reglamento (CE) n. - 764/2006, crea una comisión mixta encargada de supervisar la aplicación de dicho Acuerdo y, en particular, de supervisar su ejecución, su interpretación y el buen funcionamiento de su aplicación. Sin embargo, las 
posibilidades de pesca y la contrapartida financiera previstas en el Acuerdo de colaboración en el sector pesquero entre la Unión Europea y el Reino de Marruecos se fijaron en un protocolo, aprobado por la Decisión 2013/785/UE. La comisión mixta se reunió en Rabat del 18 al 20 de octubre de 2016 para adoptar la modificación de algunas modalidades de puesta en ejecución del Protocolo en materia de desembarque, habida cuenta de las dificultades recurrentes que acarrea el cumplimiento de esta obligación. La Comisión remitió al Consejo, antes de la citada reunión de la comisión mixta, un documento preparatorio en el que se exponían en detalle los elementos específicos de la posición prevista de la Unión.

La posición prevista de la Unión fue aprobada por el Consejo, y las modificaciones adoptadas, que se refieren al incremento de las sanciones en caso de incumplimiento de la obligación de desembarque y a la ampliación a todas las categorías sujetas a desembarque obligatorio de los incentivos económicos en caso de desembarque superior al umbral obligatorio, han de reflejarse, para lo cual se adopta la Decisión (UE) 2017/11 de la Comisión, de 5 de enero de 2017, por la que se aprueba, en nombre de la Unión Europea, la modificación del Protocolo entre la Unión Europea y el Reino de Marruecos por el que se fijan las posibilidades de pesca y la contrapartida financiera previstas en el Acuerdo de colaboración en el sector pesquero entre la Comunidad Europea y el Reino de Marruecos.

\section{E. Decisiones de ejecución}

a) El Reglamento de Ejecución (UE) n. 725/2011 de la Comisión, de 25 de julio de 2011, establece un procedimiento de aprobación y certificación de tecnologías innovadoras para reducir las emisiones de $\mathrm{CO}_{2}$ de los turismos, de conformidad con el Reglamento (CE) n. 443/2009 del Parlamento Europeo y del Consejo, de 23 de abril de 2009, por el que se establecen normas de comportamiento en materia de emisiones de los turismos nuevos como parte del enfoque integrado de la Comunidad para reducir las emisiones de $\mathrm{CO}_{2}$ de los vehículos ligeros. En este contexto, el proveedor a2solar Advanced and Automotive Solar Systems $\mathrm{GmbH}$ solicitó el 4 de 
febrero de 2016 la aprobación del techo fotovoltaico cargador de baterías como ecoinnovación, adjuntando la información que demuestra que se han cumplido las condiciones y los criterios exigidos. Por tanto, tras su evaluación se aprobó como tecnología innovadora el techo fotovoltaico cargador de baterías propuesto por el solicitante. Este tipo de tecnología no era la primera vez que se había solicitado y aprobado, y, sobre la base de la experiencia adquirida en la evaluación de esas solicitudes, así como de la solicitud que nos ocupa, se ha demostrado de manera satisfactoria y concluyente que un techo fotovoltaico cargador de baterías cumple los criterios de idoneidad contemplados en el artículo 12 del Reglamento (CE)

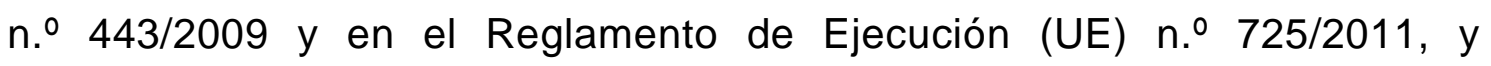
consigue una reducción de las emisiones de $\mathrm{CO}_{2}$ de al menos $1 \mathrm{~g}$ de $\mathrm{CO}_{2} / \mathrm{km}$ con respecto a un vehículo de referencia. Procede, por tanto, reconocer en general y, de conformidad con el artículo 12, apartado 4, del Reglamento (CE) $n .-943 / 2009$, aprobar esta tecnología innovadora como capaz de reducir las emisiones de $\mathrm{CO}_{2}$, así como prever una metodología de ensayo genérica para la certificación de las reducciones de las emisiones de $\mathrm{CO}_{2}$. Por tanto, se adopta la Decisión de Ejecución (UE) 2016/1926 de la Comisión, de 3 de noviembre de 2016, relativa a la aprobación del techo fotovoltaico cargador de baterías como tecnología innovadora para la reducción de las emisiones de $\mathrm{CO}_{2}$ de los turismos de conformidad con el Reglamento (CE) n. $.443 / 2009$ del Parlamento Europeo y del Consejo.

b) El despacho a libre práctica en la Unión de sustancias reguladas importadas está sujeto a límites cuantitativos. La Comisión debe determinar esos límites y asignar cuotas a empresas. Además, la Comisión debe determinar las cantidades de sustancias reguladas distintas de los hidroclorofluorocarburos que pueden utilizarse para usos esenciales de laboratorio y análisis y las empresas que pueden utilizarlas. La Comisión publicó un anuncio dirigido a las empresas que tenían la intención de importar en la Unión Europea, o exportar desde esta, sustancias reguladas que agotan la capa de ozono en 2017 y a las empresas que tenían la intención de solicitar una cuota para 2017 con objeto de utilizar dichas 
sustancias para usos de laboratorio y análisis, y, en respuesta, recibió declaraciones sobre las importaciones previstas para 2017.

En virtud de todo ello, se adopta la Decisión de Ejecución (UE) 2016/2114 de la Comisión, de 30 de noviembre de 2016, por la que se determinan los límites cuantitativos y se asignan cuotas de sustancias reguladas en el

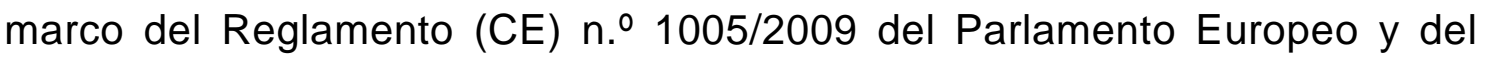
Consejo, sobre las sustancias que agotan la capa de ozono, para el período comprendido entre el 1 de enero y el 31 de diciembre de 2017.

c) En varios países de la Unión sucede que la cantidad de semillas de base disponibles de determinadas variedades que cumplen las condiciones previstas en la Directiva 2002/54/CE resultan insuficientes y, por tanto, no permite satisfacer las necesidades de comercialización de dichos Estados miembros.

En consecuencia, debe autorizarse la comercialización de semillas de estas variedades sujetas a requisitos menos estrictos. Además, procede autorizar que otros Estados miembros puedan suministrar a dichos países semillas de estas variedades. Se adopta la Decisión de Ejecución (UE) 2016/2241 de la Comisión, de 9 de diciembre de 2016, por la que se establece la comercialización temporal de semillas de determinadas variedades de la especie Beta vulgaris L. que no cumplen los requisitos de la Directiva 2002/54/CE del Consejo, y la Decisión de Ejecución (UE) 2016/2242 de la Comisión, de 9 de diciembre de 2016, por la que se establece la comercialización temporal de semillas de la variedad Scrabble de Hordeum vulgare L. que no cumplen los requisitos de la Directiva 66/402/CEE del Consejo.

Además, dado que las presentes decisiones introducen una excepción respecto a los requisitos de la normativa de la Unión, procede limitar la cantidad de semillas que cumplen requisitos menos estrictos al mínimo necesario para satisfacer las necesidades de estos Estados. Con el fin de garantizar que la cantidad total de semillas cuya comercialización se autoriza con arreglo a las presentes decisiones no exceda de las cantidades máximas establecidas en dichas decisiones, procede que 
Dinamarca y España actúen como Estados coordinadores, puesto que han presentado la correspondiente solicitud de adopción de las presentes decisiones y son los máximos interesados en la comercialización de esta variedad.

d) En materia de biocidas debemos destacar la Decisión de Ejecución (UE) 2016/2318 de la Comisión, de 16 de diciembre de 2016, relativa a una excepción por parte de España al reconocimiento mutuo de las autorizaciones de los biocidas que contienen brodifacum, con arreglo al artículo 37 del Reglamento (UE) n. 528/2012 del Parlamento Europeo y del Consejo [notificada con el número C(2016) 8414].

e) El Reglamento (UE) n. 1257/2013 establece los requisitos que deben cumplir los propietarios de buques, las administraciones y las organizaciones reconocidas en relación con la expedición, refrendo, prórroga y presencia a bordo de los certificados de buque listo para el reciclado. De conformidad con dicha regulación, los buques destinados a ser reciclados deben disponer de un certificado de buque listo para el reciclado. Asimismo, establece los requisitos que deben cumplir las empresas de reciclado de buques, las instalaciones de reciclado de buques y los responsables de la explotación de instalaciones de reciclado de buques en relación con el reciclado de buques que enarbolan pabellón de un Estado miembro de la Unión. Para ello, el responsable de la explotación de la instalación de reciclado de buques debe enviar, en los catorce días siguientes a la fecha de reciclado total o parcial de conformidad con el plan de reciclado del buque, una declaración de conclusión a la Administración que entregó el certificado de idoneidad para el reciclado del buque. Igualmente, el responsable de la explotación de la instalación de reciclado de buques está obligado a comunicar a la Administración que la instalación de reciclado de buques está lista a todos los efectos para comenzar el reciclado.

A tales efectos, se adoptan la Decisión de Ejecución (UE) 2016/2321 de la Comisión, de 19 de diciembre de 2016, sobre el formato del certificado de buque listo para el reciclado, expedido de conformidad con el Reglamento (UE) n. $\cong$ 1257/2013 del Parlamento Europeo y del Consejo, relativo al 
reciclado de buques, la Decisión de Ejecución (UE) 2016/2322 de la Comisión, de 19 de diciembre de 2016, sobre el formato de la declaración de conclusión del reciclado del buque exigida de conformidad con el Reglamento (UE) n. 1257/2013 del Parlamento Europeo y del Consejo, relativo al reciclado de buques, y la Decisión de Ejecución (UE) 2016/2324 de la Comisión, de 19 de diciembre de 2016, sobre el formato del informe del inicio previsto del reciclado del buque exigido de conformidad con el Reglamento (UE) n.o 1257/2013 del Parlamento Europeo y del Consejo, relativo al reciclado de buques.

Además, en esta materia se adopta la Decisión de Ejecución (UE) 2016/2323 de la Comisión, de 19 de diciembre de 2016, por la que se establece la lista europea de instalaciones de reciclado de buques con

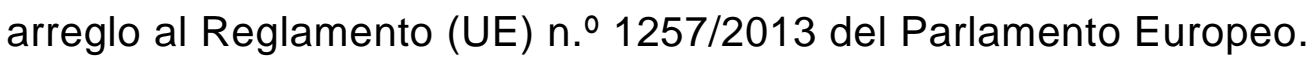

f) Los espacios incluidos en la lista de lugares de importancia comunitaria (LIC) de las diferentes regiones de la Unión Europea forman parte de la red Natura 2000, que es una red de áreas de conservación de la biodiversidad en la Unión Europea. Consta de zonas especiales de conservación (ZEC), designadas de acuerdo con la Directiva de Hábitats, así como de zonas de especial protección para las aves (ZEPA), establecidas en virtud de la Directiva de Aves. Su finalidad es asegurar la supervivencia a largo plazo de las especies y los hábitats más amenazados de Europa, contribuyendo a detener la pérdida de biodiversidad ocasionada por el impacto adverso de las actividades humanas. Es el principal instrumento para la conservación de la naturaleza en la Unión Europea. A fin de seguir avanzando en el establecimiento concreto de la red Natura 2000, y en el marco de la adaptación dinámica de dicha red, las listas de lugares de importancia comunitaria se revisan periódicamente, puesto que los conocimientos sobre la existencia y distribución de especies y tipos de hábitats naturales evolucionan constantemente.

En este sentido, en el período entre el 16 de enero de 2015 y el 15 de febrero de 2016, los Estados miembros propusieron lugares de importancia comunitaria adicionales de diferentes regiones a tenor del artículo 1 de la Directiva 92/43/CEE. Asimismo, comunicaron cambios en la información 
contenida en la lista de lugares de importancia comunitaria de estas. Por tanto, procede actualizar las listas de los lugares de importancia comunitaria de diferentes hábitats y regiones, para lo cual se adoptan las siguientes decisiones: la Decisión de Ejecución (UE) 2016/2328 de la Comisión, de 9 de diciembre de 2016, por la que se adopta la décima lista actualizada de lugares de importancia comunitaria de la región biogeográfica mediterránea; la Decisión de Ejecución (UE) 2016/2329 de la Comisión, de 9 de diciembre de 2016, por la que se adopta la cuarta lista actualizada de lugares de importancia comunitaria de la región biogeográfica del Mar Negro; la Decisión de Ejecución (UE) 2016/2330 de la Comisión, de 9 de diciembre de 2016, por la que se adopta la sexta lista actualizada de lugares de importancia comunitaria de la región biogeográfica macaronésica; la Decisión de Ejecución (UE) 2016/2331 de la Comisión, de 9 de diciembre de 2016, por la que se adopta la décima lista actualizada de lugares de importancia comunitaria de la región biogeográfica boreal; la Decisión de Ejecución (UE) 2016/2332 de la Comisión, de 9 de diciembre de 2016, por la que se adopta la décima lista actualizada de lugares de importancia comunitaria de la región biogeográfica alpina; la Decisión de Ejecución (UE) 2016/2333 de la Comisión, de 9 de diciembre de 2016, por la que se adopta la octava lista actualizada de lugares de importancia comunitaria de la región biogeográfica panónica; la Decisión de Ejecución (UE) 2016/2334 de la Comisión, de 9 de diciembre de 2016, por la que se adopta la décima lista actualizada de lugares de importancia comunitaria de la región biogeográfica continental; y la Decisión de Ejecución (UE) 2016/2335 de la Comisión, de 9 de diciembre de 2016, por la que se adopta la décima lista actualizada de lugares de importancia comunitaria de la región biogeográfica atlántica.

g) Decisión de Ejecución (UE) 2017/487 de la Comisión, de 17 de marzo de 2017, que modifica la Decisión 2005/51/CE en lo que respecta al período durante el cual puede introducirse en la Unión tierra contaminada con plaguicidas o contaminantes orgánicos persistentes a efectos de su descontaminación [notificada con el número C(2017) 1693]. Por medio de la 
Decisión 2005/51/CE de la Comisión, se autorizó temporalmente a los Estados miembros a establecer una excepción a esas disposiciones, en determinadas condiciones, con respecto a la tierra contaminada con plaguicidas o contaminantes orgánicos persistentes importada a efectos de su descontaminación y destinada al tratamiento en incineradores dedicados específicamente a residuos peligrosos. Algunos Estados miembros han pedido que se prorrogue la autorización para establecer esa excepción. De la información presentada por los Estados miembros con arreglo a la Decisión 2005/51/CE se deduce que, al aplicar esa excepción, se han cumplido las condiciones específicas establecidas en dicha Decisión, y que estas condiciones son suficientes para impedir que se introduzcan en la Unión organismos nocivos. Por consiguiente, la actividad contemplada en la Decisión 2005/51/CE no plantea ningún riesgo fitosanitario. Conviene, pues, prorrogar hasta el 31 de diciembre de 2019 la autorización para establecer la excepción.

h) Decisión de Ejecución (UE) 2017/499 de la Comisión, de 17 de marzo de 2017, relativa a la creación de la Infraestructura Virtual Europea de Ciencia y Tecnología para la Investigación sobre la Biodiversidad y los Ecosistemas - Consorcio de Infraestructuras de Investigación Europeas (LifeWatch ERIC) [notificada con el número C(2017) 1648]. Bélgica, Grecia, España, Italia, los Países Bajos, Portugal, Rumanía y Eslovenia solicitaron a la Comisión la creación de la Infraestructura Virtual Europea de Ciencia y Tecnología para la Investigación sobre la Biodiversidad y los Ecosistemas - Consorcio de Infraestructuras de Investigación Europeas (LifeWatch ERIC). Han convenido en que España sea el Estado miembro de acogida de LifeWatch ERIC. La Comisión, de conformidad con el artículo 5, apartado 2, del Reglamento (CE) n. $-723 / 2009$, ha evaluado la solicitud y ha concluido que cumple los requisitos establecidos en dicho Reglamento.

i) Decisión de Ejecución (UE) 2017/487 de la Comisión, de 17 de marzo de 2017, que modifica la Decisión 2005/51/CE en lo que respecta al período durante el cual puede introducirse en la Unión tierra contaminada con plaguicidas o contaminantes orgánicos persistentes a efectos de su descontaminación [notificada con el número C(2017) 1693]. Por medio de la 
Decisión 2005/51/CE de la Comisión, se autorizó temporalmente a los Estados miembros a establecer una excepción a esas disposiciones, en determinadas condiciones, con respecto a la tierra contaminada con plaguicidas o contaminantes orgánicos persistentes importada a efectos de su descontaminación y destinada al tratamiento en incineradores dedicados específicamente a residuos peligrosos. Algunos Estados miembros han pedido que se prorrogue la autorización para establecer esa excepción. De la información presentada por los Estados miembros con arreglo a la Decisión 2005/51/CE se deduce que, al aplicar esa excepción, se han cumplido las condiciones específicas establecidas en dicha Decisión, y que estas condiciones son suficientes para impedir que se introduzcan en la Unión organismos nocivos. Por consiguiente, la actividad contemplada en la Decisión 2005/51/CE no plantea ningún riesgo fitosanitario. Conviene, pues, prorrogar hasta el 31 de diciembre de 2019 la autorización para establecer la excepción.

\section{F. Directiva de Ejecución}

En la lista del artículo 2, apartado 1, letra A, letra a), de la Directiva 66/401/CEE aparece Lolium $x$ boucheanum Kunth. La Asociación Internacional de Análisis de Semillas ha cambiado recientemente la denominación botánica de Lolium $x$ boucheanum Kunth a Lolium $x$ hybridum Hausskn. Por consiguiente, procede modificar la denominación de dicha especie en la Directiva 66/401/CEE. Y, por ello, se adopta la Directiva de Ejecución (UE) 2016/2109 de la Comisión, de 1 de diciembre de 2016, por la que se modifica la Directiva 66/401/CEE del Consejo en lo que respecta a la inclusión de nuevas especies y al nombre botánico de la especie Lolium $x$ boucheanum Kunth.

\section{G. Dictámenes y comunicaciones}

El 29 de marzo de 2016, la Comisión Europea recibió del Gobierno alemán, de conformidad con el artículo 37 del Tratado Euratom, los datos generales relativos al plan para la evacuación de los residuos radiactivos resultantes de la clausura y el desmantelamiento de la central nuclear Unterweser KKU. 
Sobre la base de esos datos y de la información adicional solicitada por la Comisión el 4 de julio de 2016 y facilitada por las autoridades alemanas el 18 de agosto de 2016, y previa consulta al grupo de expertos, la Comisión ha elaborado el Dictamen de la Comisión, de 26 de enero de 2017, relativo al plan de evacuación de los residuos radiactivos resultantes de la clausura y el desmantelamiento de la central nuclear Unterweser KKU, situada en Alemania, de conformidad con el artículo 37 del Tratado Euratom, en el cual considera improbable que la aplicación del plan de evacuación de los residuos radiactivos, cualquiera que sea su forma, derivados de la clausura y desmantelamiento de la central nuclear Unterweser KKU, situada en Alemania, tanto en caso de funcionamiento normal como en caso de accidente del tipo y magnitud considerados en los datos generales, dé lugar a una contaminación radiactiva del agua, el suelo o el espacio aéreo de otro Estado miembro que sea significativa desde el punto de vista sanitario, en relación con lo dispuesto en la Directiva sobre normas básicas de seguridad, así como en la nueva Directiva sobre normas básicas de seguridad.

\subsection{Otros}

\section{A. Comité de las Regiones}

Se adopta el Dictamen del Comité Europeo de las Regiones - Propuestas legislativas por las que se modifican las Directivas 2000/53/CE, relativa a los vehículos al final de su vida útil, 2006/66/CE, relativa a las pilas y acumuladores y a los residuos de pilas y acumuladores, y 2012/19/UE, sobre residuos de aparatos eléctricos y electrónicos - COM (2015) 593 final - 2015/0272 (COD), (2017/C 017/09).

El principal objetivo de esta Directiva es minimizar el impacto negativo de las pilas sobre el medio ambiente, evitando el vertido de sustancias peligrosas (metales pesados) al medio ambiente. Establece normas para la puesta en el mercado de pilas y su eliminación especial.

Los Estados miembros fomentan la investigación sobre métodos de reciclaje económicos y respetuosos con el medio ambiente para todo tipo 
de pilas y acumuladores. Las pilas orgánicas son una nueva generación de pilas que no contienen materiales peligrosos. Por toda Europa se llevan a cabo actividades de investigación e innovación. Además de sus componentes seguros para el medio ambiente, las pilas tienen un gran potencial económico y una amplia gama de aplicaciones.

Sin la enmienda propuesta, las pilas orgánicas estarán sujetas a los requisitos de eliminación especial para pilas convencionales, a pesar de ser ecológicas. Esto supondría un obstáculo a la innovación tecnológica dirigida a la consecución de los objetivos medioambientales, y también evitaría que esta innovación contribuyese al crecimiento y al empleo en Europa. En consecuencia, las pilas orgánicas deben excluirse del ámbito de aplicación de la presente Directiva.

\section{B. Comité Económico y Social}

a) El Comité Económico y Social (en adelante, el Comité) adopta el Dictamen sobre la "Propuesta de Reglamento del Parlamento Europeo y del Consejo sobre la conservación de los recursos pesqueros y la protección de los ecosistemas marinos con medidas técnicas, y por el que se modifican los Reglamentos (CE) n. 1967/2006, (CE) n. 1098/2007 y (CE) n.은 1224/2009 del Consejo y los Reglamentos (UE) n.ำ 1343/ 2011 y (UE) n.으. 1380/2013 del Parlamento Europeo y del Consejo, y por el que se derogan los Reglamentos (CE) n. 894/97, (CE) n.. 850/98, (CE) n. 2549/2000, (CE) n. ${ }^{\circ}$ 254/2002, (CE) n. ${ }^{\circ} 812 / 2004$ y (CE) n. ${ }^{\circ} 2187 / 2005$ del Consejo" [COM(2016) 134 final - 2016/0074 (COD)](2016/C 389/09). Comparte plenamente el enfoque de la Comisión sobre la necesidad de actualizar y simplificar el sistema actual de gobernanza de las medidas técnicas, que debe basarse en una estrategia a largo plazo en materia de gestión y conservación de los recursos, dada la complejidad y abundancia de normas en la materia.

Asimismo, considera que varias de las novedades y modificaciones propuestas ayudarían de manera directa a la adaptación de la flota a la obligación de desembarque y el rendimiento máximo sostenible, pues se trata de reformas que ofrecerían una mayor flexibilidad operativa y 
promoverían una mayor selectividad de las artes, y como tal las acoge favorablemente.

Sin embargo, entiende que algunas de las propuestas se han presentado sin tomar plenamente en consideración las condiciones prácticas de las actividades pesqueras y sin valorar los efectos económicos y sociales. Así, el Comité no está convencido de que estas propuestas sean un compromiso razonable entre la salvaguardia de los intereses a corto y medio plazo del sector pesquero y una mejor conservación de los recursos pesqueros. En este sentido, se ha de prestar una atención especial a los aspectos siguientes:

1. Pide a la Comisión que reconsidere los cambios en los tamaños de las mallas que se proponen y que utilice las mallas de referencia que vienen siendo usadas por la flota para las diferentes pesquerías, sin que haya aumentos o disminuciones injustificados o innecesarios.

2. Reitera la importancia de no introducir en la propuesta modificaciones de las tallas mínimas que vienen aplicándose para algunas especies sin la debida justificación.

3. Considera que se deberían introducir normas que permitan la innovación y la creación de valor para las capturas no deseadas.

4. Insta a la flexibilización de los topes de capacidad pesquera medidos en arqueo bruto, impuestos a los Estados miembros por la política pesquera común para adaptar los buques y favorecer la mejora de las condiciones de trabajo a bordo.

Para finalizar, el Comité solicita al Consejo, al Parlamento Europeo y a la Comisión que se establezca un auténtico diálogo con los pescadores y sus representantes antes de adoptar cualquier decisión sobre las propuestas planteadas, puesto que el cumplimiento de las normas requiere el acuerdo tácito y la cooperación de los pescadores y se tienen mayores posibilidades de aplicarse si los pescadores participan plenamente en el debate.

b) El tráfico de especies silvestres no es un fenómeno nuevo, pero su escala, su naturaleza y sus efectos han cambiado considerablemente en los 
últimos años. El rápido y vasto aumento del tráfico de especies silvestres conlleva que, con un volumen de negocios estimado de entre 8.000 y 20.000 millones de euros al año, sea una de las formas más graves de delincuencia organizada junto con la trata de personas y el tráfico de drogas y armas. Por ello, se adopta el Dictamen del Comité Económico y Social Europeo sobre la Comunicación de la Comisión al Parlamento Europeo, al Consejo, al Comité Económico y Social Europeo y al Comité de las Regiones - Plan de acción de la UE contra el tráfico de especies silvestres [COM(2016) 87 final], (2016/C 389/10), en el cual se acoge favorablemente la propuesta de la Comisión sobre un plan de acción de la Unión Europea contra el tráfico de especies silvestres, y considera que el enfoque holístico, incluida una alianza mundial que integre a los países de origen, tránsito y demanda, es un pilar fundamental para la lucha contra las consecuencias directas e indirectas del tráfico de especies silvestres. Para ello, se deben implantar un diálogo y una cooperación estructurados con los terceros países mediante la inclusión de la lucha contra el tráfico de especies silvestres como un requisito previo para todos los acuerdos comerciales bilaterales y multilaterales de la Unión Europea.

El Comité identifica distintas acciones prioritarias para los diferentes niveles de la cadena de suministro del tráfico:

1. A escala comunitaria en los países de origen, la prioridad debe ser tanto la sensibilización como la creación de fuentes sostenibles de empleo y de ingresos.

2. En cuanto a la delincuencia organizada, la prioridad es tanto imponer un sistema de controles comunes, eficaces, proporcionales y disuasivos como facilitar los recursos necesarios para los esfuerzos policiales.

3. Con respecto a la demanda, tanto desde el punto de vista de las empresas como de los consumidores, la prioridad debe ser la concienciación, la trazabilidad y el etiquetado. Esto debería aplicarse de manera específica a nivel europeo. 
4. En el ámbito judicial, la prioridad debe situarse en el cumplimiento de la ley mediante la formación específica de los jueces para garantizar la coherencia y la proporcionalidad de las condenas.

El Comité lamenta que en la propuesta de la Comisión no se haga referencia a la amenaza que supone el tráfico de especies silvestres para la salud pública y para las especies animales y vegetales autóctonas, y hace hincapié en que los sistemas de etiquetado y trazabilidad antes mencionados, junto con un mecanismo adecuado de controles veterinarios y fitosanitarios, pueden contribuir a contrarrestar la aparición y propagación de estas enfermedades a escala mundial. Además, de conceder una importancia mucho mayor a las repercusiones del comercio electrónico.

c) El Dictamen del Comité Económico y Social Europeo sobre "La política de biodiversidad de la UE" (2016/C 487/03) recuerda que la política de biodiversidad de la Unión es un ejemplo clásico de una política de promesas incumplidas a escala europea y nacional, a pesar de que el sector político ha identificado correctamente cuáles son los problemas y establecido los instrumentos necesarios. El Comité aboga por una aplicación consecuente y rápida de la Directiva de Aves y la Directiva de Hábitats. De igual modo, la aplicación rápida y consecuente de la Directiva Marco del Agua también aportaría una contribución significativa a una mejor protección de la biodiversidad.

Asimismo, los Estados miembros tendrán que determinar las necesidades financieras específicas que se derivan de la aplicación de la legislación de la UE, y la Comisión deberá poner a disposición los fondos necesarios. Dado que la financiación de la red Natura 2000 a través de los fondos comunitarios, esencialmente, el Fondo Europeo de Desarrollo Regional y el Fondo Europeo Agrícola de Desarrollo Rural, se considera que ha fracasado en muchos ámbitos, solicita la creación de un presupuesto autónomo destinado a la financiación de la red Natura 2000.

Además, apuesta por consolidar la coherencia entre todas las políticas que influyen en la protección de la biodiversidad. En este contexto, espera que tanto la revisión intermedia de las "superficies de interés ecológico" como 
una posible revisión intermedia de la Política Agrícola Común se utilicen para que contribuyan en el futuro de forma más adaptada a la consecución de los objetivos en materia de biodiversidad.

Se acoge con gran satisfacción la consolidación de la infraestructura verde. En este contexto, el Comité pide a la Comisión y a los Estados miembros que preparen y apliquen una estrategia coherente de infraestructura verde. Asimismo, la Unión debe hacer de las redes transeuropeas verdes (RTE-V) una prioridad de inversión. A tal efecto, también es imperativo incrementar los fondos asignados.

Por consiguiente, el Comité constata una vez más, como ya lo ha hecho en muchos de sus dictámenes anteriores sobre la política de biodiversidad en la Unión, que lo que falta es la voluntad política, no los fundamentos jurídicos. No es necesario modificar la base jurídica existente.

d) Dictamen del Comité Económico y Social Europeo sobre "Energía marina: fuentes de energía renovable por desarrollar" (2017/C 034/08). Desde hace años, científicos e ingenieros estudian la explotación de la energía de los océanos. Corrientes, mareas y fuerza del oleaje albergan reservas de energía indefinidamente renovables. El Comité considera interesante, por tanto, desarrollar este tipo de producción de electricidad renovable y no centrarse solo en las tecnologías eólicas y la energía solar. Es cierto que la energía marina no se puede explotar en todas partes, pero sería un error descuidar una fuente de energía renovable previsible y con un impacto medioambiental bajo o controlable. Es sabido que el futuro energético se basará en la variedad de las fuentes de abastecimiento. Ya existen algunos ejemplos; en Francia, la planta mareomotriz de EDF en Rance, inaugurada en 1966 por el general De Gaulle, tiene una capacidad de $240 \mathrm{MW}$, con veinticuatro turbinas de $10 \mathrm{MW}$ cada una. Las eólicas de última generación generan, en el mejor de los casos, $8 \mathrm{MW}$. Por tanto, esta tecnología es eficaz, aun cuando la presa de Rance ha sido durante mucho tiempo el único ejemplo mundial de una instalación de este tipo. Hoy existe otro ejemplo comparable en el lago de Sihwa, en Corea del Sur, con una capacidad de $254 \mathrm{MW}$. Para terminar, destaca que invertir en este ámbito 
permitiría a la Unión situarse, a medio plazo, a la vanguardia de las nuevas fuentes de energía renovables. 